\title{
The Scincid Lizard Genus Caledoniscincus (Reptilia: Scincidae) from New Caledonia in the Southwest Pacific: A Review of Caledoniscincus austrocaledonicus (Bavay) and Description of Six New Species from Province Nord
}

\author{
Ross A. SAdlier, ${ }^{1}$ Aaron M. BAuer ${ }^{2} \&$ Don J. Colgan ${ }^{3}$ \\ ${ }^{1}$ Herpetology Section, Australian Museum, 6 College Street, Sydney NSW 2000, Australia \\ rosss@amsg.austmus.gov.au \\ ${ }^{2}$ Department of Biology, Villanova University, 800 Lancaster Avenue, Villanova, Pennsylvania 19085, USA \\ abauer@king-kong.csc.vill.edu \\ ${ }^{3}$ Evolutionary Biology Unit, Australian Museum, 6 College Street, Sydney NSW 2000, Australia \\ donc@amsg.austmus.gov.au
}

\begin{abstract}
The status of the New Caledonian scincid lizard Caledoniscincus austrocaledonicus (Bavay) is reviewed and found to comprise two species. The species conspecific with the designated neotype is widespread and morphologically diverse, the other is conspecific with Euprepes haplorhinus Günther and is also widespread in distribution. These two species occur in sympatry over much of their range, particularly on the west coast. Six new species of Caledoniscincus are described from the central and northern regions of the island, bringing to eleven the total number of species in the genus. The new species are restricted to closed forest habitat and have limited distributions, hence they are all regarded as vulnerable to disturbance of this habitat type. The eight species dealt with in this paper are recognised on the basis of combined morphological and genetic (allozyme) analysis of 36 populations representing all members in the genus.
\end{abstract}

SAdlier, Ross A., Aaron M. BAuer \& Don J. Colgan, 1999. The scincid lizard genus Caledoniscincus (Reptilia: Scincidae) from New Caledonia in the Southwest Pacific: a review of Caledoniscincus austrocaledonicus (Bavay) and description of six new species from Province Nord. Records of the Australian Museum 51(1): 57-82.

Some of the most common and widespread elements of the New Caledonian lizard fauna are the small scincid species in the genus Caledoniscincus. The last revision of the genus (Sadlier, 1986) identified four species, C. austrocaledonicus, C. atropunctatus, C. festivus, and C. orestes, all characterised by marked sexual dimorphism in colour and pattern. Caledoniscincus austrocaledonicus, C. festivus and $C$. atropunctatus are widespread throughout the island, whereas $C$. orestes at the time of description (1986) was only known from mid-high (600-1,400 m asl) habitats on 
Mt Panié in the northeast ranges. The four species were distinguished from one another mainly by coloration (particularly that of males) and size.

Extensive field research in New Caledonia over the past 5 years has revealed Caledoniscincus to be a far more diverse group than previously suspected. The widespread species $C$. austrocaledonicus has been found to comprise two species, one of which is conspecific with Euprepes haplorhinus Günther (formerly a synonym of $C$. austrocaledonicus). In the central and northern regions of the island six new taxa are known from areas of closed forest habitat. Several of the undescribed species are known from only single localities or small geographical areas, while the remainder are restricted to larger, but still discrete regions. In a south to north order the new species described are: $C$. cryptos known only from a single specimen in the central ranges (near Col d'Amieu); C. renevieri known from several localities in the central ranges (Col des Roussettes, Mt Aoupinié, and Grottes des Adio); C. chazeaui from one, possibly two, locations near limestone outcrops on the northeast coast (near Hienghène); C. aquilonius from a number of localities in the northern ranges; $C$. auratus from one, possibly two, locations near limestone outcrops on the northwest coast (near Koumac); and C. terma known only from Mt Mandjélia at the northern tip of the northeast ranges. Because of the localised nature of their distributions and the range of threats to closed forest habitat in New Caledonia, most of the new taxa described in this paper are considered to be of particular conservation concern.

\section{Materials and methods}

Abbreviations. Institutional abbreviations are as follows: Australian Museum (AMS); The Natural History Museum, London (BMNH); California Academy of Sciences (CAS); Naturhistorisches Museum, Basel (NHMB); Muséum national d'Histoire naturelle, Paris (MNHN).

The full suite of morphological characters listed below were scored for each specimen where possible. For each character the abbreviation used in Table 3 is given in parentheses.

Measurements. Snout to vent length (SVL) - measured from tip of snout to caudal edge of anal scales; axilla to groin distance-measured from middle of base of forelimb to middle of base of hindlimb; forelimb to snout lengthmeasured from tip of snout to middle of base of forelimb; hindlimb length - measured from middle of base of hindlimb to tip of fourth toe including nail; tail length (TL) - measured from caudal edge of anal scales to tip of tail, on complete original tails only. Body measurements (axilla to groin, forelimb to snout, hindlimb, and tail lengths) are for adults only, as determined by reproductive maturity (presence of enlarged yolked ovarian follicles or eggs in females, and presence of enlarged testes and distinctive coloration in males) and/or obvious size classes, and are expressed as percentages of snout to vent length in the taxon accounts.

Scalation. Midbody scale rows (MBR) - number of longitudinal scale rows around body counted midway between axilla and groin; paravertebral scales (DSR)- number of scales in a paravertebral row from first scale posterior to parietal scale to last scale at level of vent opening; fourth finger and toe scales-number of dorsal scales on fourth digit of hand and foot, distal scale contains claw and basal scale broadly contacts adjacent basal scale of third finger or toe; fourth finger and toe lamellaenumber of ventral scales on fourth digit of hand and foot, distal scale contains claw and basal scale is last largely undivided scale at, or proximal to, a point level with intersection of third and fourth digits. Bilateral scalation characters were scored on both sides and the mean value used in description of each species; in the holotype descriptions these values are presented as left/right values. Sexual dimorphism in paravertebral scales (the scalation character most likely to exhibit this trait) was assessed using independent two-sample $t$-test in those species represented by a moderately large sample size $(=10$ specimens with approximately equal numbers of each sex). Variation between populations was assessed using independent twosample $t$-tests for all scalation characters. However, only characters with a high $\mathrm{P}$ value $(\mathrm{P} \leq 0.001)$ are given in the comparison of species as these most likely reflect unambiguous species level differences.

Osteology. Specimens were $X$-rayed for counting the number of presacral vertebrae and postsacral vertebrae (complete original tails only).

Electrophoretic methods. Standard methods for cellulose acetate electrophoresis of liver homogenates on TITAN III plates (Helena Laboratories) were used to assess genetic relationships between populations (Hebert \& Beaton, 1989; Colgan \& Flannery, 1992; Sadlier et al., 1993). Where more than one locus encoding the same enzyme was found, they are designated numerically in order of decreasing anodal mobility. Allozymes are designated (alphabetically) in the same fashion for each locus. The computer package BIOSYS-1 (Swofford \& Selander, 1981) was used to calculate genetic distances and to perform cluster analyses. Where Idhp- $l$ was not seen in the phenotype of a population, it was scored as being homozygous null (with a dummy allelic designation in BIOSYS-1) for the purposes of distance calculations.

\section{Results}

The electrophoretic results are presented in Tables 1 and 2. Table 1 shows the number of individuals scored from each population of the species described herein and from Caledoniscincus orestes. In both Tables 1 and $2 C$. austrocaledonicus and C. haplorhinus are each represented by pooled populations. A more detailed account of variation in C. austrocaledonicus will be presented elsewhere. The names of the scored enzymes, together with abbreviations and Enzyme Commission Numbers are also listed in Table 1, and a matrix of genetic distances between Caledoniscincus populations is given in Table 2. A UPGMA dendrogram of genetic distances between populations is shown in Figure 1. Eight groups can be clearly distinguished. The Nei Unbiased distance between any pair of populations from different groups is at least 0.25 . 


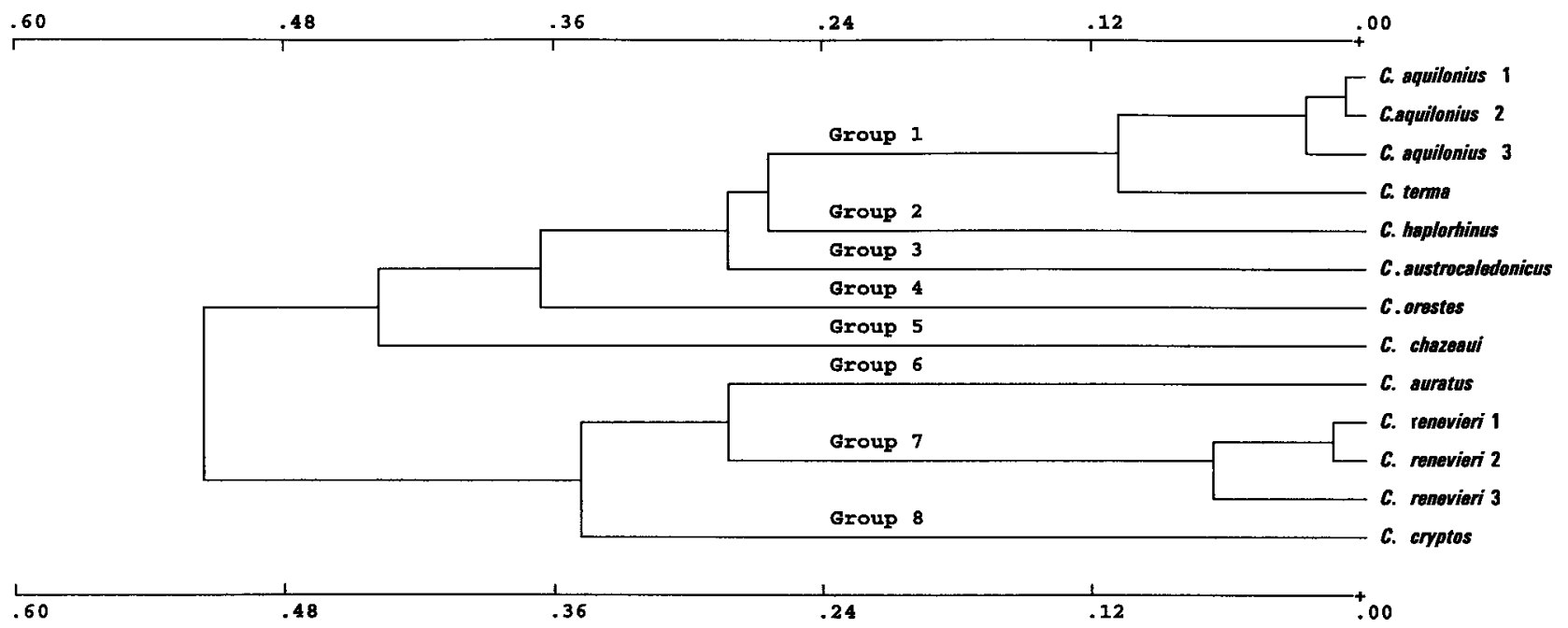

Figure 1. UPGMA dendrogram of relationships between Caledoniscincus populations based on Nei's unbiased genetic distance. Population names are the same as in Table 1.

Group 1 includes 4 populations from the far north of the island separated from group 2, the next most genetically similar group, by a Nei unbiased genetic distance of 0.27 . Within group 1 are two subgroups (with a Nei unbiased genetic distance of 0.10) that are here described as two species on the basis of consistent morphological differences (coloration, scalation, osteology) between the type populations of each species. The first species, Caledoniscincus aquilonius, is represented in the genetic study by three populations, one from Koumac (C. aquilonius 1 ), one from Mt Panié ( $C$. aquilonius 2 ) here designated as the type population, and the third from Kavaatch $(C$. aquilonius 3); the second species, Caledoniscincus terma, consists of a single population from Mt Mandjélia.

Groups 2 and 3 comprise those populations formerly assigned to Caledoniscincus austrocaledonicus. Our studies show $C$. austrocaledonicus to be a single widespread species that exhibits marked dimorphism in colour and pattern between northern and southern populations. A second widespread species, Caledoniscincus haplorhinus, occurs in open coastal and near coastal habitats, mainly on the west coast of the island, but also at scattered localities on the east coast and in the Loyalty Islands. Caledoniscincus haplorhinus is similar in size and appearance to Caledoniscincus austrocaledonicus from the north and central regions of the island, most notably in also having a white midlateral stripe. Both species are regionally and often locally sympatric along the west coast. The formal recognition of these genetic groups as distinct species is supported by differences in adult male ventral coloration and the positioning and delineation of the white midlateral stripe.

Group 2 represents Caledoniscincus haplorhinus (5 populations pooled - all from the west coast of the island).

Group 3 represents Caledoniscincus austrocaledonicus s.str. (20 populations pooled) as defined above.

Group 4 represents Caledoniscincus orestes from Mt Panié on the northeast ranges as defined by Sadlier (1986).
Groups 5, 6, and 7 are recognised as distinct species on the basis of a combination of scalation and electrophoretic criteria, while group 8 (a single adult male) is currently recognised solely on electrophoretic criteria.

Group 5 (Caledoniscincus chazeaui) represents a population from closed forest in the area of limestone rock outcropping on the northeast coast near Hienghène. Group 5 is separated from groups 1 to 4 by a Nei unbiased distance of 0.44 .

Groups 6-8 form a discrete cluster separated from groups $1-5$ by a Nei unbiased distance of 0.51 .

Group 6 (Caledoniscincus auratus) consists of a single population from Koumac (where it is sympatric with $C$. aquilonius 2) on the northwest coast. Group 6 is separated from group 7, the next most genetically similar group, by a Nei unbiased distance of 0.28

Group 7 (Caledoniscincus renevieri) comprises three populations in the central ranges of the island: Mt Aoupinié (C. renevieri 1$)$, Grottes des Adio (C. renevieri 2$)$, and Col des Roussettes (C. renevieri 3 ).

Group 8 (Caledoniscincus cryptos), represented by a single individual from near Col d'Amieu in the central ranges, is separated from those populations in the group 6 +7 , the next most genetically similar group, by a Nei unbiased distance of 0.35 .

Whilst genetic distances give a general idea of a population's affinities, inspection of the allozymic frequency data is required for a clearer picture. Notably, each of the groups defined above (except groups 1 and 6) are fixed, for at least one locus, for an allozyme which is seen nowhere else in the data. For Group 2 (C. haplorhinus) such allozymes are found at both Idhp- 1 and Idhp-2, for Group 3 (C. austrocaledonicus) at Aat-1, for Group 4 (C. orestes) at $F h$-2 and Idhp-2, for Group 5 (C. chazeaui) at Aat-1, for Group 7 (C. renevieri) at Idhp-1, and for Group 8 (C. cryptos) at Gapdh. Inspection of the data in Table 1 reveals sufficient fixed differences ("fds") between groups (with the possible exception of $C$. aquilonius and C. terma) 
to support all of the taxonomic decisions made below. For instance, $C$. aquilonius and C. terma are differentiated from Group 2 by fds at $G p d, I d h p-1, I d h p-2$ and (nearly fixed) $P g m$. Caledoniscincus renevieri and $C$. auratus are differentiated by fds at Idhp-1, Pep:LA, Pep:LGG and Pgdh. Caledoniscincus cryptos is distinguished from both of these species by fds at Fbp, Gapdh and Gpd. There are two fds between the morphospecies $C$. aquilonius and $C$. terma (Idhp-2 and Pgdh) and the GPI C allozyme which is common, but not abundant, in the former is apparently absent from the latter.

\section{Species descriptions}

The species dealt with in this paper are small to moderately large in size, with well-developed limbs and digits, long tails, an obvious ear opening, and share the following basic suite of scalation characters: frontonasal broader than long; prefrontals when present moderately large and widely separated; frontal almost as broad as long; supraoculars four; frontoparietals fused; interparietal distinct; parietal bordered by a nuchal and upper secondary temporal; primary temporal single; upper and lower secondary temporals single; tertiary temporals two; postlabials two; nasals moderately to widely separated; loreals two, in a horizontal sequence; upper and lower preocular present; supraciliaries usually 7; upper labials usually 7; lower labials 6; postmental contacting first and second lower labials; enlarged chinshields three, first pair in broad contact; lower eyelid with an obvious, centrally located semi-transparent disc; ear opening with enlarged auricular lobules anteriorly and numerous blunt conical scales around the upper, lower, and posterior edges; body scales of dorsal and lateral surfaces tricarinate, each keel usually interrupting the posterior scale edge, number of keels on dorsal scales increasing towards nape. All species also have 29 presacral vertebrae (occasionally 28 or 30 ) and a phalangeal formula for the manus and pes of 2.3.4.5.3 and 2.3.4.5.4 respectively.

The species accounts below describe variation in proportions, and certain features of scalation, osteology, and coloration for each species, and report on their distribution and habits.

\section{Caledoniscincus austrocaledonicus (Bavay)}

Figs. 2, 3

Lygosoma austro-caledonica Bavay, 1869: 21.

Lygosoma austro-caledonicum dorsovittatum Roux, 1913: 118. Leiolopisma dorsovittatum bodoi Borner, 1980: 8.

Problems in resolving the taxonomy of Caledoniscincus austrocaledonicus stem from the sexual and regional variability in coloration in this species, its occurrence in the north of the island with a closely related and morphologically very similar species, and the apparent loss of the specimens upon which the original description was based. The history of synonyms for this species are presented chronologically below.

The description of Lygosoma austro-caledonica by Bavay (1869) is composite (Sadlier, 1986) in that it identifies two forms. It was one of eight new scincid
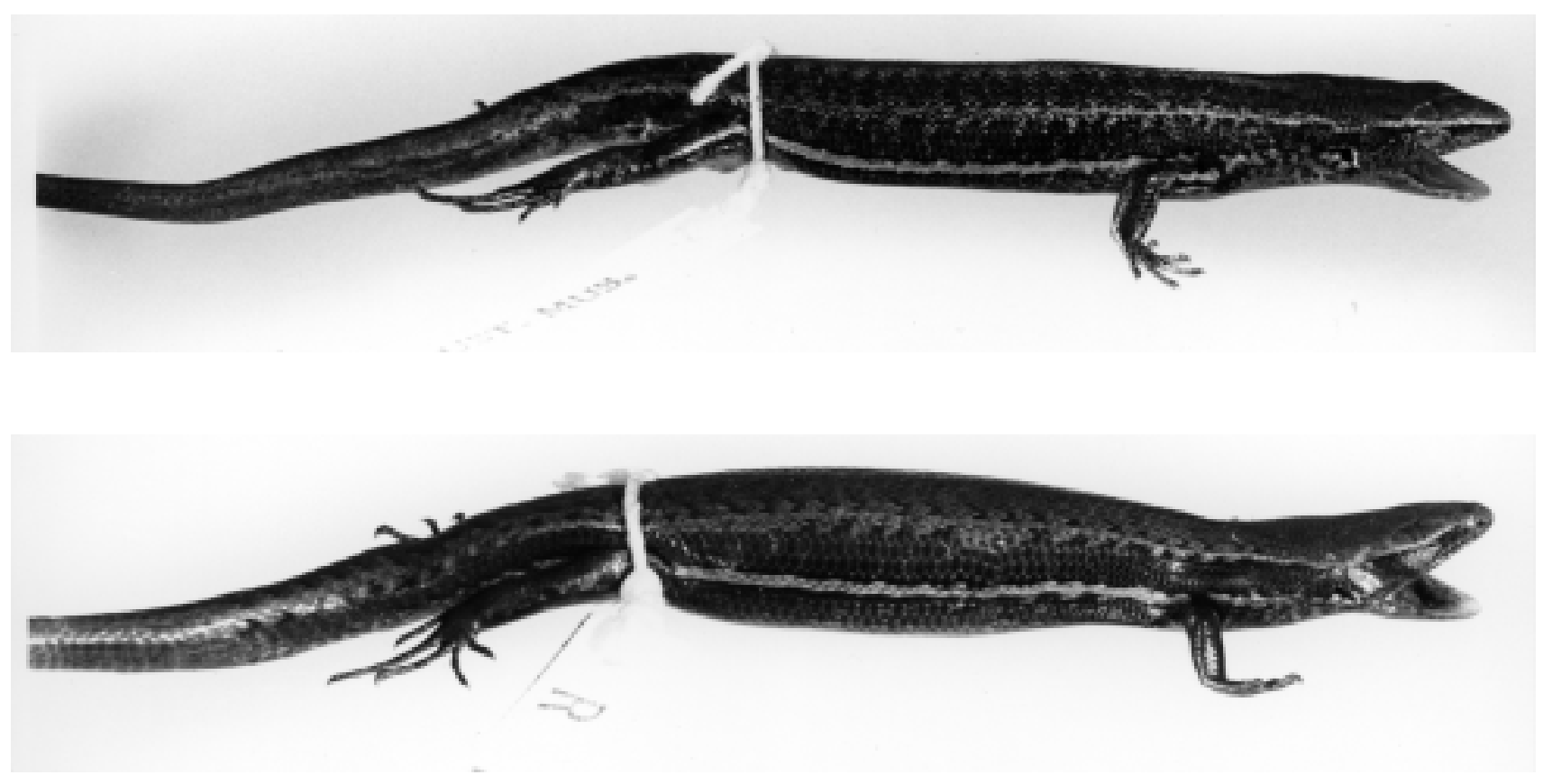

Figure 2. Caledoniscincus austrocaledonicus male (upper) and female (lower) from Mt Aoupinié. 
lizards described by him from New Caledonia for which no types were designated at the time of description, nor any indication as to where the specimens on which the descriptions were based were lodged.

The species Euprepes haplorhinus described by Günther (1872) from the Fiji Islands was placed in the synonymy of L. austro-caledonicum by Boulenger (1887) and the locality of "Fiji" was indicated as being in error for New Caledonia.

The first major revision of the New Caledonian herpetofauna was by Roux in 1913, based mainly on collections made by Roux and Sarasin in New Caledonia in 1911. Roux recognised four subspecies in Lygosoma austro-caledonicum. In addition to the nominate form, Roux described three new subspecies: Lygosoma austrocaledonicum dorsovittatum; Lygosoma austro-caledonicum atropunctatum; and Lygosoma austro-caledonicum festivum. Roux considered Lygosoma austro-caledonicum atropunctatum represented one of the forms of Lygosoma austro-caledonica described by Bavay (1869), and Euprepes haplorhinus Günther (1872) a synonym of Lygosoma austro-caledonicum. Kramer (1979) subsequently designated lectotypes for all Roux's subspecies of Lygosoma austro-caledonicum.

Borner (1980) described the subspecies Leiolopisma dorsovittatum bodoi from the Ile des Pins.

Brygoo (1985) published a catalogue of scincid types in the Paris Museum which included a number of Bavay type specimens that had until that time been regarded as lost (Sadlier, 1986). However the types of Lygosoma austrocaledonicum Bavay were not among those listed.

Sadlier (1986) reviewed the taxonomy of Caledoniscincus and proposed a neotype for Lygosoma austro-caledonicum Bavay, an adult female from Mt Aoupinié in the central ranges. In colour and pattern this specimen is typical of females found in populations occurring in the central and northern ranges and coast of New Caledonia. Roux's subspecies Lygosoma austro-caledonicum atropunctatum and Lygosoma austro-caledonicum festivum were recognised as distinct species by Sadlier (1986), and Euprepes haplorhinus Günther, Lygosoma austrocaledonicum dorsovittatum Roux, and Leiolopisma dorsovittatum bodoi Borner were all placed in the synonymy of $C$. austrocaledonicus.

The research presented here clearly identifies Lygosoma austro-caledonicum Bavay and Euprepes haplorhinus Günther as distinct species. Lygosoma austro-caledonicum dorsovittatum Roux and Leiolopisma dorsovittatum bodoi Borner are regarded here as conspecific with Lygosoma austro-caledonicum Bavay.

Material examined. All from Mt Aoupinié as follows: AMS R77643-45, R77649 forestry camp, $21^{\circ} 09^{\prime} \mathrm{S} 165^{\circ} 20^{\prime} \mathrm{E}$; R77690, R77692 $2 \mathrm{~km} \mathrm{NE}$ of Mt Aoupinié forestry camp by road, $21^{\circ} 08^{\prime} \mathrm{S} 165^{\circ} 21^{\prime} \mathrm{E}$; R77707, R77710-14, R146369 creek crossing $1 \mathrm{~km} \mathrm{NE}$ of forestry camp by road, $21^{\circ} 08^{\prime} \mathrm{S} 165^{\circ} 20^{\prime} \mathrm{E}$; R77739-40, R77755-56, R146379 summit, $21^{\circ} 11^{\prime} \mathrm{S} 165^{\circ} 16^{\prime} \mathrm{E}$; R77757 (NEOTYPE), R77758 $4 \mathrm{~km}$ from summit by road, $21^{\circ} 11^{\prime} \mathrm{S}$ $165^{\circ} 16^{\prime} \mathrm{E}$; R77759-61 $6 \mathrm{~km}$ from summit by road, $21^{\circ} 11^{\prime} \mathrm{S}$ $165^{\circ} 16^{\prime} \mathrm{E}$; R146376-77 creek $1.3 \mathrm{~km}$ below logging camp, $21^{\circ} 08^{\prime} \mathrm{S} 165^{\circ} 20^{\prime} \mathrm{E}$; R146386 1.5-2.5 km below logging camp, $21^{\circ} 07^{\prime} \mathrm{S} 165^{\circ} 19^{\prime} \mathrm{E}$
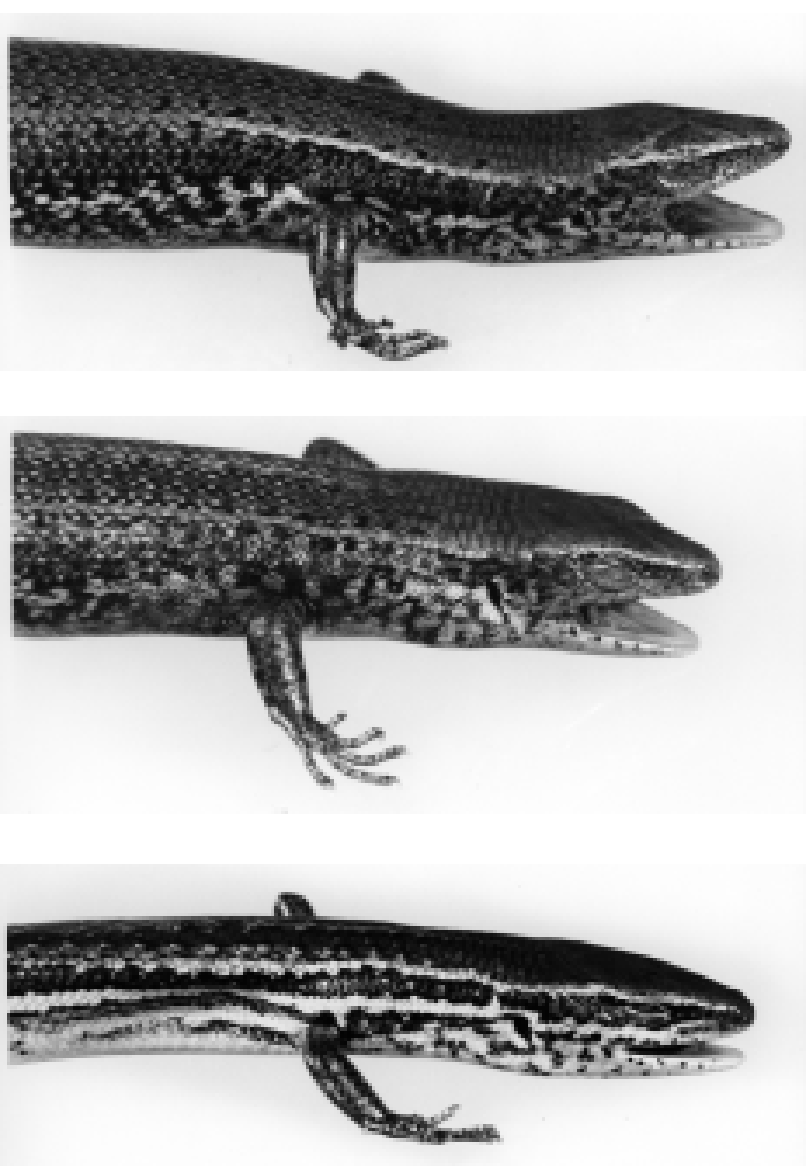

Figure 3. Lateral view of Caledoniscincus austrocaledonicus (upper and middle) and Caledoniscincus haplorhinus (lower) showing positioning of pale midlateral stripe in region of ear opening.

Diagnosis. Caledoniscincus austrocaledonicus is a widespread and morphologically variable species that shows variation in coloration between sexes and between populations in the south and north of the main island. It can be distinguished from the other species of Caledoniscincus by the following combination of characters: (a) moderately small size (39-57 mm SVL); (b) tail approximately 1.5 times longer than body; $(c)$ midbody scales in 28-32 rows; $(d)$ paravertebral scales in 56-65 rows; $(e)$ postsacral vertebrae $>46$; $(f)$ adult males with pale vertebral markings and usually a broad, pale dorsolateral margin; $(g)$ lateral surface with (northern and central populations) or without (southern) a pale midlateral stripe; $(h)$ rostral shield with a dark midrostral streak; $(i)$ adult males with an orange flush to the ventral surface in life. Note that estimates of tail length and postsacral vertebrae number are derived from populations other than those represented in Table 3.

This combination of characters distinguishes Caledoniscincus austrocaledonicus from all other members of the genus with the exception of $C$. haplorhinus. Caledoniscincus austrocaledonicus from the northern and central regions of the island are very similar in size, scalation, and certain aspects of coloration to $C$. 
haplorhinus, most notably in also having a pale midlateral stripe. However, in C. austrocaledonicus from the northern and central regions of the island this stripe is usually poorly defined or obscure in the area between the forelimbs and ear opening (Fig. 3), and when obvious anteriorly this stripe meets the ear opening at the posteromedial edge. In contrast, the pale midlateral stripe in $C$. haplorhinus is usually well defined along its entire length and meets the ear at the upper or posteromedial edge of the ear and extends forward to form a pale edging over the ear (Fig. 3). The ventral colour in life of adult male $C$. austrocaledonicus is usually orange whereas adult male $C$. haplorhinus usually have yellow venters. Caledoniscincus terma is similar to $C$. austrocaledonicus from the southern regions of the island in having pale vertebral markings and no pale midlateral stripe. However, C. austrocaledonicus from this region have a longer tail (>45 vs 35-38 postsacral vertebrae or a tail length of $\approx 150$ vs $130-140 \%$ SVL) than C. terma, and the ventral colour in life of adult male $C$. austrocaledonicus is usually orange $v s$ usually yellow in adult male $C$. terma.

Description. It is beyond the scope of this study to analyse inter and intra population variation in scalation or osteology in C. austrocaledonicus. The data presented in the following description is based on 28 specimens (16 males and 12 females) from the neotype population (including the neotype) at Mt Aoupinié in the central ranges ( $C$. austrocaledonicus [north] of Table 3).

Measurements: adult size 44-57 mm SVL; distance from axilla to groin $52.9-61.4 \%$ of SVL $(\bar{x}=56.6, n=28)$; distance from forelimb to snout $33.3-41.3 \%$ of SVL ( $\bar{x}=$ $37.7, \mathrm{n}=28)$; hindlimb length $33.3-46.8 \%$ of SVL $(\overline{\mathrm{x}}=$ $41.2, \mathrm{n}=28)$; tail length approximately $150 \%$ of SVL estimated from individual with most complete tail.

Scalation. midbody scales in 30-32 rows $(\overline{\mathrm{x}}=31.2, \mathrm{SD}=$ $0.99, \mathrm{n}=28)$; paravertebral scales in 58-65 rows $(\overline{\mathrm{x}}=61.2$, $\mathrm{SD}=1.84, \mathrm{n}=28)$, no significant variation $(\mathrm{P}$ value $\leq 0.05)$ between males and females $\left(\overline{\mathrm{X}}=61.2\right.$ vs $61.3, t_{26}=-0.204, \mathrm{P}$ $=0.840)$; dorsal scales of fourth finger $11-12(\overline{\mathrm{x}}=11.3, \mathrm{SD}$ $=0.40, \mathrm{n}=28)$; lamellae of fourth finger 15-18 $(\overline{\mathrm{x}}=16.5$, $\mathrm{SD}=0.69, \mathrm{n}=28)$; dorsal scales of fourth toe $16-19(\overline{\mathrm{x}}=$ $17.0, \mathrm{SD}=0.56, \mathrm{n}=28)$; lamellae of fourth toe $26-33(\overline{\mathrm{x}}=$ $28.7, \mathrm{SD}=1.74, \mathrm{n}=28$ ).

Osteology. Presacral vertebrae $29(\mathrm{n}=15)$, rarely $28(\mathrm{n}$ $=1$ ); no specimens with complete, original tails in sample to assess postsacral vertebrae number but specimen with most complete original tail has $>50$ postsacral vertebrae.

Coloration. Caledoniscincus austrocaledonicus shows marked sexual dimorphism in base colour of the dorsal and lateral surfaces. In males the dorsal and lateral colour is similar and the ventral surface usually red-orange. In females the dorsal surface is lighter than the lateral surface i.e. markedly two-toned, and the ventral surface is usually yellow. Juveniles and subadults of both sexes have the colour and pattern of adult females. The colour description below is based on specimens from the neotype locality at Mt. Aoupinié in the central ranges, but is broadly applicable to other populations of $C$. austrocaledonicus in the central and northern regions of the island.

Males: dorsal surface of body mid to dark brown with numerous pale flecks and distinctive pale vertebral markings, grey-brown in colour, rough-edged, and extending variably from nape to mid-dorsum as a stripe $(\approx 1$ scale wide) before breaking into a series of poorly connected elongate blotches over posterior half of body; head lighter than dorsum, with a coppery flush and dark longitudinal streak on rostrum. Dorsolateral margin pale (usually colour same as pale vertebral markings), moderately broad ( $\approx 1-1.5$ scales wide), and forming a conspicuous rough-edged stripe from rostral to and along the basal portion of tail, distinct from both dark dorsal and upper lateral colour. Lateral surface mid-dark brown and with a pale midlateral stripe; upper lateral surface similar to dark dorsal colour but darker than lower lateral surface; pale midlateral stripe rough-edged and extending from level of ear opening to base of hindlimb (sometimes broken by an extension of dark brown colour of forelimb onto adjacent lateral surface), usually poorly defined or obscure in area between forelimbs and ear opening, when obvious anteriorly pale midlateral stripe meets ear opening at posteromedial edge; area above and in front of ear opening same as adjacent lateral surface, occasionally with numerous white markings which coalesce around upper edge of ear opening (resembling the extension of pale midlateral stripe characteristic of $C$. haplorhinus but not as well defined or complete). Ventral surface from level of forelimbs to basal portion of tail and underside of fore and hindlimbs orange, continuing variably along underside of tail.

Females: dorsal surface light to mid brown; laterodorsal margin (scale row 3) with dark markings to every second or third scale to give appearance of a longitudinal series of dark flecks, dorsolateral edge distinct, variably with a pale (lighter than adjacent dorsal colour), narrow (less than a scale width), margin. Lateral surface mid-dark brown (contrasting markedly with adjacent dorsal surface) and with a pale midlateral stripe; upper lateral surface darker than lower; pale midlateral stripe clean-edged and extending from level of ear opening to base of hindlimb, definition of pale midlateral stripe as for males (above). Ventral surface from level of forelimbs to basal portion of tail and underside of fore and hindlimbs yellow, continuing variably along underside of tail.

Variation. Data in Table 3 indicate populations of Caledoniscincus austrocaledonicus from the south of the species range tend to be smaller in size, have fewer midbody scale rows and paravertebral scales, and in coloration lack a pale midlateral stripe.

Regional differences in the presence or absence of a pale midlateral stripe in Caledoniscincus austrocaledonicus have confused previous taxonomies. Populations which share the coloration characteristics of the neotype (a well-developed midlateral stripe) extend throughout the central and northern regions of the island, the southernmost populations occurring at Voh on the west coast, Col des Roussettes in the central mountain chain, and Houaillou on the east coast. In the central mountain chain populations immediately south of Col des Roussettes have this coloration characteristic poorly expressed (males lack a pale midlateral stripe but some females have a poorly defined stripe), and those that occur in the south of the island (this is the area at and south of the northern limit of the extensive southern ultramafic 
region), the Ile des Pins, and the Loyalty Islands do not have this coloration characteristic.

Details of neotype. Adult female; size $53 \mathrm{~mm} \mathrm{SVL}$; distance from axilla to groin $32 \mathrm{~mm}$; distance from forelimb to snout $19 \mathrm{~mm}$; hindlimb length $19 \mathrm{~mm}$; tail length $66 \mathrm{~mm}$, regenerated.

Midbody scales rows 30; paravertebral scale rows 59; dorsal scales of fourth finger 11/12; lamellae of fourth finger 16/16; dorsal scales of fourth toe 16/16; lamellae of fourth toe $27 / 27$.

Distribution. The species is widespread throughout New Caledonia and the islands of the region including the Ile des Pins, and Ouvéa, Lifou, and Maré in the Loyalty Islands group.

Biology. Caledoniscincus austrocaledonicus occurs throughout a wide range of forest and shrubland habitats across a broad altitudinal range. It is most commonly observed at the forest edge or in sunlit patches on the forest floor, but also occurs in coastal scrubs and maquis shrubland habitat. It is sympatric with $C$. haplorhinus at various lowland localities in both the north and south of New Caledonia and the islands of the region. In the north of the island the two species are sympatric at several mid-high altitude locations. Where the two species do occur at the same location, $C$. austrocaledonicus inhabits the forest edge and open areas of the forest interior, whereas $C$. haplorhinus occurs in more open adjacent habitat and tends to be extralimital at the forest edge. In such situations both species are syntopic at the forest edge.

Comments. The description of Caledoniscincus austrocaledonicus by Sadlier (1986) was composite and contained specimens of $C$. haplorhinus.

Other material examined. With the exception of tail length and postsacral vertebrae the values presented in Table 3 for $C$. austrocaledonicus from the south of the island (austro sth.) are taken from the following material: AMS R77442-43, R77445, R77448, R78309, R78311-12, R78315, R78324 Nouméa, Fambourg Blanchot (rue de Capitain Ferraud), 20 $18^{\circ} \mathrm{S} 166^{\circ} 27^{\prime} \mathrm{E}$; R77470 Nouméa, Mont-Coffyn, $20^{\circ} 18^{\prime} \mathrm{S} 166^{\circ} 27^{\prime} \mathrm{E}$. Values for tail length and postsacral vertebrae presented in Table 3 are taken from a sample of two specimens from Plateau de Dogny.

\section{Caledoniscincus haplorhinus Günther}

Figs. 3, 4

Euprepes haplorhinus Günther, 1872: 419.

\section{Type material. HOLOTYPE: BMNH 1946.8.13.45.}

Material examined. AMS R77407, R77409, R77427, R77437, R77449-52，R 78319-20，R78322，R78326-28 Nouméa, Fambourg Blanchot, $20^{\circ} 18^{\prime} \mathrm{S} 16^{\circ} 27^{\prime} \mathrm{E}$; AMS R135119-23 Isle Nou, vicinity Nouville, $22^{\circ} 16^{\prime} \mathrm{S} 166^{\circ} 24^{\prime} \mathrm{E}$; AMS R146433-43,

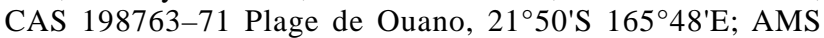
R144257-58, R144284-93 Koumac Caves, approx. 9 km E of
Koumac, 20³3'S $164^{\circ} 21^{\prime} E$; AMS R146459-72 Pindaï, Plage de Pindaï, $21^{\circ} 21^{\prime} \mathrm{S} 164^{\circ} 57^{\prime} \mathrm{E}$.

Diagnosis. Caledoniscincus haplorhinus can be distinguished from the other species of Caledoniscincus by the following combination of characters: $(a)$ moderately small size (42-55 mm SVL); (b) tail approximately 1.65 times longer than body; $(c)$ midbody scales in 28-32 rows; $(d)$ paravertebral scales in 59-67 rows; $(e)$ postsacral vertebrae >50; $(f)$ adult males with pale vertebral markings and broad pale dorsolateral margin; $(g)$ lateral surface with a pale midlateral stripe; $(h)$ rostral shield with a dark midrostral streak; $(i)$ adult males with a yellow flush to ventral surface in life.

Description. the description is based on 61 specimens (51 adults and 10 subadults) and includes samples from four (Isle Nou, Plage de Ouano, Koumac Caves and Pindaï) of the five populations used in the electrophoretic study.

Measurements. Maximum adult size $55 \mathrm{~mm} \mathrm{SVL}$; distance from axilla to groin $51.0-63.3 \%$ of SVL $(\bar{x}=$ $57.0, \mathrm{n}=50)$; distance from forelimb to snout $34.7-$ $40.4 \%$ of SVL $(\bar{x}=37.6, n=50)$; hindlimb length $33.3-$ $42.5 \%$ of SVL $(\bar{x}=38.8, \mathrm{n}=49)$; tail length 156.0 $173.5 \%$ of SVL $(\bar{x}=165.1, n=4-$ note this includes 3 adults with nearly complete tail only).

Scalation. Midbody scales in $28-32$ rows $(\overline{\mathrm{x}}=30.0$, SD $=1.06, \mathrm{n}=61)$; paravertebral scales in 59-67 rows $(\overline{\mathrm{x}}=$ $63.0, \mathrm{SD}=1.63, \mathrm{n}=61)$ significant variation $(\mathrm{P}$ value $\leq 0.05)$ between males and females $\left(\overline{\mathrm{x}}=62.5\right.$ vs $63.5, t_{49}=-2.535, \mathrm{P}$ $=0.014)$; dorsal scales of fourth finger $10-12(\overline{\mathrm{x}}=10.9, \mathrm{SD}$ $=0.62, \mathrm{n}=60)$; lamellae of fourth finger $14-18(\overline{\mathrm{x}}=15.8$, $\mathrm{SD}=0.67, \mathrm{n}=60)$; dorsal scales of fourth toe $14-18(\overline{\mathrm{x}}=$ $16.6, \mathrm{SD}=0.91, \mathrm{n}=60)$; lamellae of fourth toe $25-31(\overline{\mathrm{x}}=$ 28.0, $\mathrm{SD}=1.38, \mathrm{n}=60)$.

Osteology. Presacral vertebrae $29(\mathrm{n}=12)$; postsacral vertebrae $51(\mathrm{n}=2)$ to $55(\mathrm{n}=1)$.

Coloration. Males: dorsal surface mid to dark brown with numerous pale flecks and distinct pale vertebral markings, grey-brown in colour, rough-edged, and extending from nape to mid-dorsum as a stripe before breaking into a series of poorly connected elongate blotches over posterior half of body; head lighter than dorsum, with a coppery flush and dark longitudinal streak on rostrum. Dorsolateral margin pale (grey-brown similar to pale vertebral markings), moderately broad ( $\approx 1-1.5$ scales wide), and forming a conspicuous rough-edged stripe from rostral to and along basal portion of tail, distinct from both dark dorsal and upper lateral colour. Lateral surface mid-dark brown and with a pale midlateral stripe, upper lateral surface darker than lower lateral surface (darker than or similar to dorsal colour); pale midlateral stripe (usually dark edged) well defined along its entire length and extending from level of ear opening to base of hindlimb, meeting ear at upper or posteromedial edge and extending forward to form a pale edging over the ear. Ventral surface from level of forelimbs to basal portion of tail and underside of fore and hindlimbs with a yellow flush, continuing variably along underside of tail.

Females: dorsal surface light to mid brown, occasionally grey, uniform or with variably distinct pale vertebral 

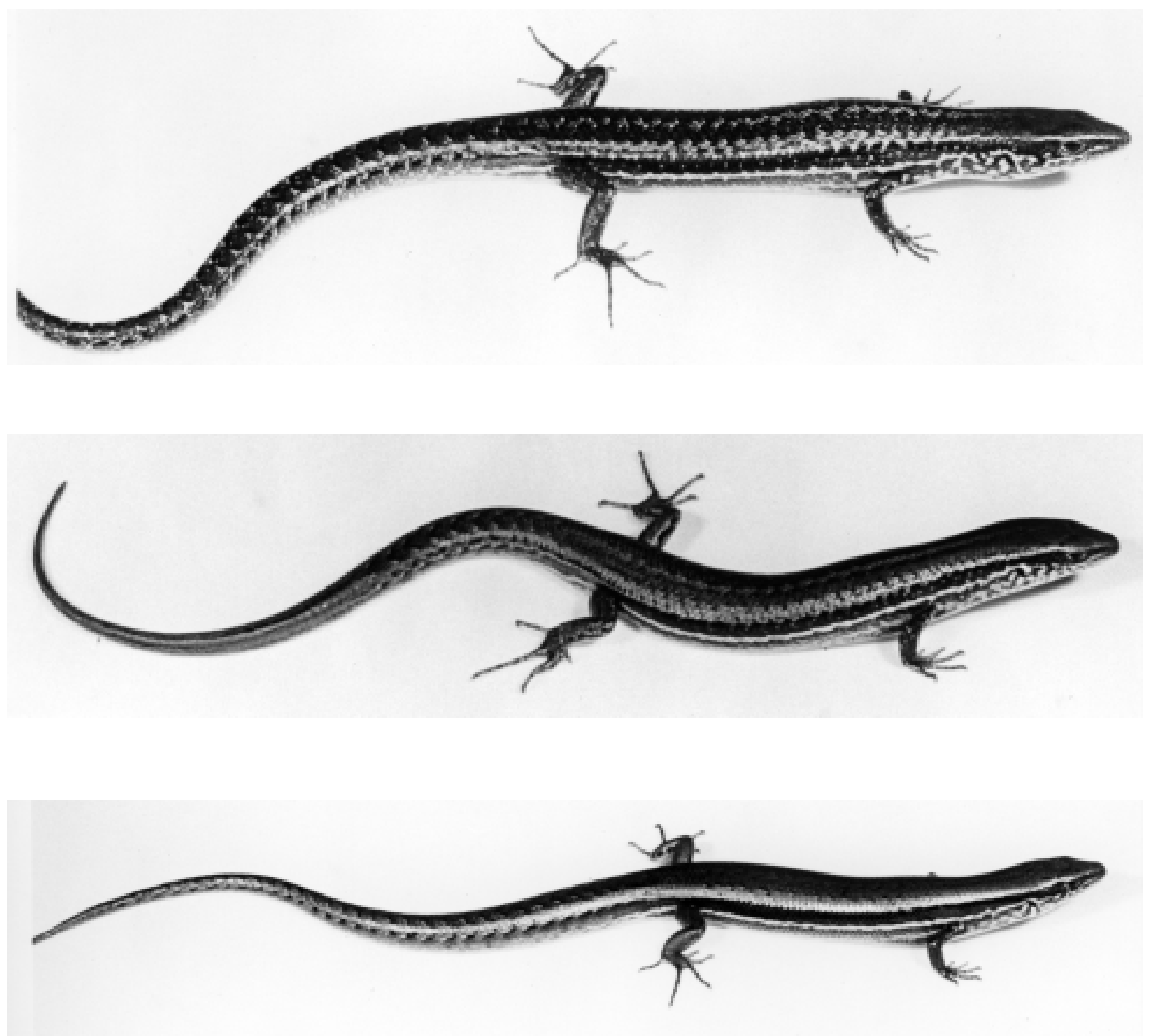

Figure 4. Caledoniscincus haplorhinus males from Pindaï (upper) and Koumac (middle), and female from Koumac (lower).

markings, grey-brown in colour, and extending from nape to mid-dorsum as a stripe before breaking into a series of poorly connected elongate blotches over posterior half of the body. Lateral surface mid-dark brown (darker than and contrasting markedly with adjacent dorsal colour) with a pale midlateral stripe, upper lateral surface darker than lower lateral surface; pale (dark edged) midlateral stripe cleanedged, extending from level of ear opening to base of hindlimb, and positioned to meet ear as described for males. Ventral surface from level of forelimbs to basal portion of tail and underside of fore and hindlimbs pale yellow, continuing variably along underside of tail.

Juveniles and subadults of both sexes have coloration of adult females, and dorsal and lateral surfaces and pale midlateral stripe well defined.
Variation. Samples of both sexes from beachfront locations can be paler overall in coloration, grey replacing brown as the background tone. In some adults from these locations the definition of the pale midlateral stripe is poor anteriorly and its position relative to the ear opening difficult to assess.

Details of holotype. Adult male; size $50 \mathrm{~mm} \mathrm{SVL}$; distance from axilla to groin $28 \mathrm{~mm}$; distance from forelimb to snout $19 \mathrm{~mm}$; hindlimb length $21 \mathrm{~mm}$; tail length $64 \mathrm{~mm}$, regenerated.

Midbody scales rows 28; paravertebral scale rows 62; dorsal scales of fourth finger 11/11; lamellae of fourth finger 17/17; dorsal scales of fourth toe 17/17; lamellae of fourth toe $29 / 28$. 
Distribution. Widespread in coastal and near coastal areas of the west coast of New Caledonia, and scattered locations on the east coast from near Ouaième in the north to Houaiilou midway along the coast. Also recorded from two mid altitude sites $(\approx 500 \mathrm{~m}$ asl) and one high altitude site $(\approx 1,000 \mathrm{~m}$ asl on $\mathrm{Mt}$ Ignambi) in the northeast ranges. Widespread throughout the islands of the region including the Ile des Pins off southern New Caledonia, Ouvéa, Lifou, and Maré Islands of the Loyalty Islands group, and Ile Surprise off northern New Caledonia.

Biology. Occurs in open coastal and near coastal habitats including grassed, beachfront sand-dunes, edges of forest habitat, and disturbed areas such as plantations and urban gardens.

Caledoniscincus haplorhinus is sympatric with $C$. austrocaledonicus at a number of coastal and lowland localities throughout the main island of New Caledonia, and the islands of the region (see comments the account of C. austrocaledonicus above).

Gravid females from Plage de Ouano collected in January 1995 had $3(1 / 2, \mathrm{n}=4$, SVL $42-48 \mathrm{~mm})$ and 5 $(2 / 3, n=1$, size not determined) enlarged yolked ovarian follicles, and specimens from Nouméa collected in March 1990 had $2(1 / 1, \mathrm{n}=2,43-47 \mathrm{~mm})$ shelled oviducal eggs.

Comments. The description of Caledoniscincus austrocaledonicus by Sadlier was composite and contained specimens of $C$. haplorhinus (see comments the account of $C$. austrocaledonicus above). Specimens refereed to as $C$. austrocaledonicus from Isle Surprise (Bauer et al., 1992) are C. haplorhinus.

\section{Caledoniscincus aquilonius n.sp.}

Figs. 5, 6

Type material. HolOTYPE: AMS R144200 Mt Panié, New Caledonia, 20³3'27"S 16447'15"E (R. Sadlier, 20.viii.1994). PARATYPES: AMS R144198-204, R14420613, R144227-28, CAS 203480-82, MNHN 1997.3331-32 same location as holotype.

Etymology. The species name is from the Latin aquilonius, meaning northern, alluding to the distribution of this species in the north of New Caledonia.

Diagnosis. Caledoniscincus aquilonius can be distinguished from the other species of Caledoniscincus by the following combination of characters: (a) moderately small size (39-49 $\mathrm{mm} \mathrm{SVL}$ ); (b) tail (average) approximately 1.5 times longer than body; (c) midbody scales in 30-34 rows; $(d)$ paravertebral scales in 54-58 rows; (e) postsacral vertebrae 40-44; $(f)$ adult males with a broad pale laterodorsal margin and dorsal pattern of scattered light flecks; $(g)$ lateral surface without a pale midlateral stripe; $(h)$ rostral shield with a dark midrostral streak; $(i)$ adult males with an orange flush to the ventral surface in life.
Description. The description is based on a series of 15 specimens ( 8 males and 7 females) collected at the type location, and includes specimens used in the electrophoretic study.

Measurements. Adult size 39-49 mm SVL; distance from axilla to groin $52.2-59.2 \%$ of SVL $(\overline{\mathrm{x}}=56.2, \mathrm{n}=$ 15); distance from forelimb to snout $36.7-41.3 \%$ of SVL $(\overline{\mathrm{x}}=39.2, \mathrm{n}=15)$; hindlimb length $32.7-40.9 \%$ of SVL $(\bar{x}=37.3, n=12)$; tail length $146.3-162.8 \%$ of $\operatorname{SVL}(\bar{x}=$ 154.6, $\mathrm{n}=2$ ).

Scalation. Midbody scales in 30-34 rows $(\overline{\mathrm{x}}=32.2$, SD $=1.08, \mathrm{n}=15) ;$ paravertebral scales in $54-58$ rows $(\overline{\mathrm{x}}=$ $55.8, \mathrm{SD}=1.65, \mathrm{n}=15)$, no significant variation ( $\mathrm{P}$ value $\leq 0.05)$ between males and females $(\overline{\mathrm{x}}=55.3, \mathrm{n}=8$ vs 56.4 , $\mathrm{n}=7, t_{13}=-1.425, \mathrm{P}=0.178$ ); dorsal scales of fourth finger 9-10 $(\overline{\mathrm{x}}=9.6, \mathrm{SD}=0.46, \mathrm{n}=15)$; lamellae of fourth finger 13-16 $(\overline{\mathrm{x}}=14.4, \mathrm{SD}=0.73, \mathrm{n}=14)$; dorsal scales of fourth toe 11-14 $(\overline{\mathrm{x}}=13.0, \mathrm{SD}=0.34, \mathrm{n}=14)$; lamellae of fourth toe 23-27 ( $\overline{\mathrm{x}}=25.2, \mathrm{SD}=1.14, \mathrm{n}=14)$.

Osteology. Presacral vertebrae 29-30 ( $\overline{\mathrm{x}}=29.1, \mathrm{SD}=$ $0.26, \mathrm{n}=15)$; postsacral vertebrae 43-44 $(\mathrm{n}=2)$.

Coloration. Males: dorsal surface variable, background colour ranging from mid brown with numerous pale flecks to more or less uniformly dark brown; pale markings boldest anteriorly around region either side of forelimb and comprising a dark-edged cream fleck on every third longitudinal scale row forming a rough, transversely aligned, pale bar; dorsolateral region grey to pale brown (sometimes darker) with dark flecks, and forming a broad (usually 2 scales wide) and conspicuous pale, roughedged stripe from rostral to basal portion of the tail. Lateral surface lighter in tone than dorsal, mid-dark brown uppermost with similar pale and dark spotting as dorsal surface, becoming paler towards venter and suffused with orange ventral colour. Ventral surface from level of forelimbs to basal portion of tail and underside of fore and hindlimbs orange, continuing variably along underside of tail. Throat grey when viewed obliquely but with a faint orange wash when viewed ventrally.

Females: dorsal surface mid to dark brown with occasional fine dark spotting, particularly towards nape; scales on vertebral axis slightly lighter in colour in some individuals and giving the appearance of a faint, pale stripe down the centre of back; head lighter in colour than adjacent dorsal surface. Lateral surface dark brown to black (darker than dorsal surface) becoming paler towards the venter, unmarked or with a few scattered dark markings uppermost, and in larger individuals with a well defined pale dorsolateral margin $(\approx 1.5$ scales wide). Ventral surface from level of forelimbs to basal portion of tail and underside of fore and hindlimbs orange, continuing variably along underside of tail. Throat with numerous fine dark specks along the posterior edge of each scale giving an overall grey appearance but with a faint orange wash when viewed ventrally.

Details of holotype. Adult male; SVL $44 \mathrm{~mm}$; distance from axilla to groin $25 \mathrm{~mm}$; distance from forelimb to snout $18 \mathrm{~mm}$; hindlimb length $18 \mathrm{~mm}$; tail length $56 \mathrm{~mm}$, reproduced. 


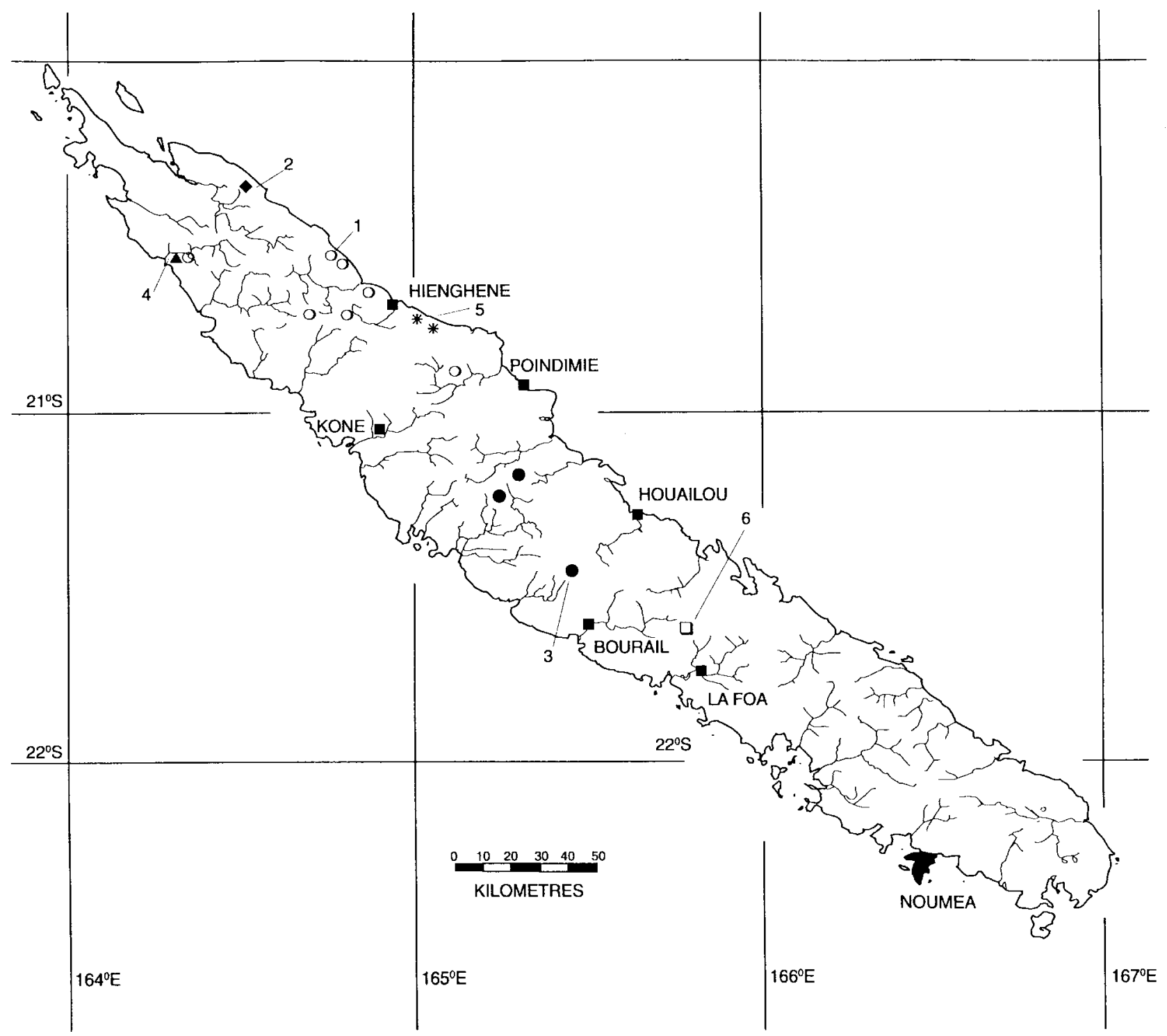

Figure 5. Distribution of six new species of Caledoniscincus in New Caledonia as follows: Caledoniscincus aquilonius (O type locality $=1)$, Caledoniscincus terma $(\checkmark$ type locality $=2)$, Caledoniscincus renevieri $(-$ type locality =3), Caledoniscincus auratus ( $\boldsymbol{\Delta}$ type locality $=4)$, Caledoniscincus chazeaui $(*$ type locality $=5$ ), and Caledoniscincus cryptos ( $\square$ type locality $=6$ ).

Midbody scales rows 32; paravertebral scale rows 56; dorsal scales of fourth finger 10/10; lamellae of fourth finger $14 / 14$; dorsal scales of fourth toe 13/13; lamellae of fourth toe $25 / 26$.

Presacral vertebrae 29.

Distribution. The type series is restricted to Mt Panié in the northeast ranges of New Caledonia (Fig. 5). Samples assigned to this species but not included in the type series are known from several other locations in the northeast coast and ranges (Kavaatch in the Hienghène Valley; Ouinguip between Hienghène and the Ouaième River; Tao near the base of Mt Panié; and upper reaches of the Hienghène Valley) and two extralimital localities, one at Koumac Caves on the northwest coast and one from the main range between
Kone and Poindimié. Caledoniscincus aquilonius is probably widespread in closed forest habitat in the north of the island.

Biology. Occurs in closed low-mid altitude forest, from near sea level at Tao to $690 \mathrm{~m}$ asl on Mt Panié.

Clutch size 3, gravid females (SVL 47 and $48 \mathrm{~mm}$ ) collected during the summer wet season (January) contained oviducal eggs $(1 / 2, n=2)$.

Comments. The type series is restricted to the sample of specimens from Mt Panié which unambiguously represented a single species based on the genetic and morphological data are available. In both the Kavaatch and Koumac samples polymorphic allele's with no evidence of 

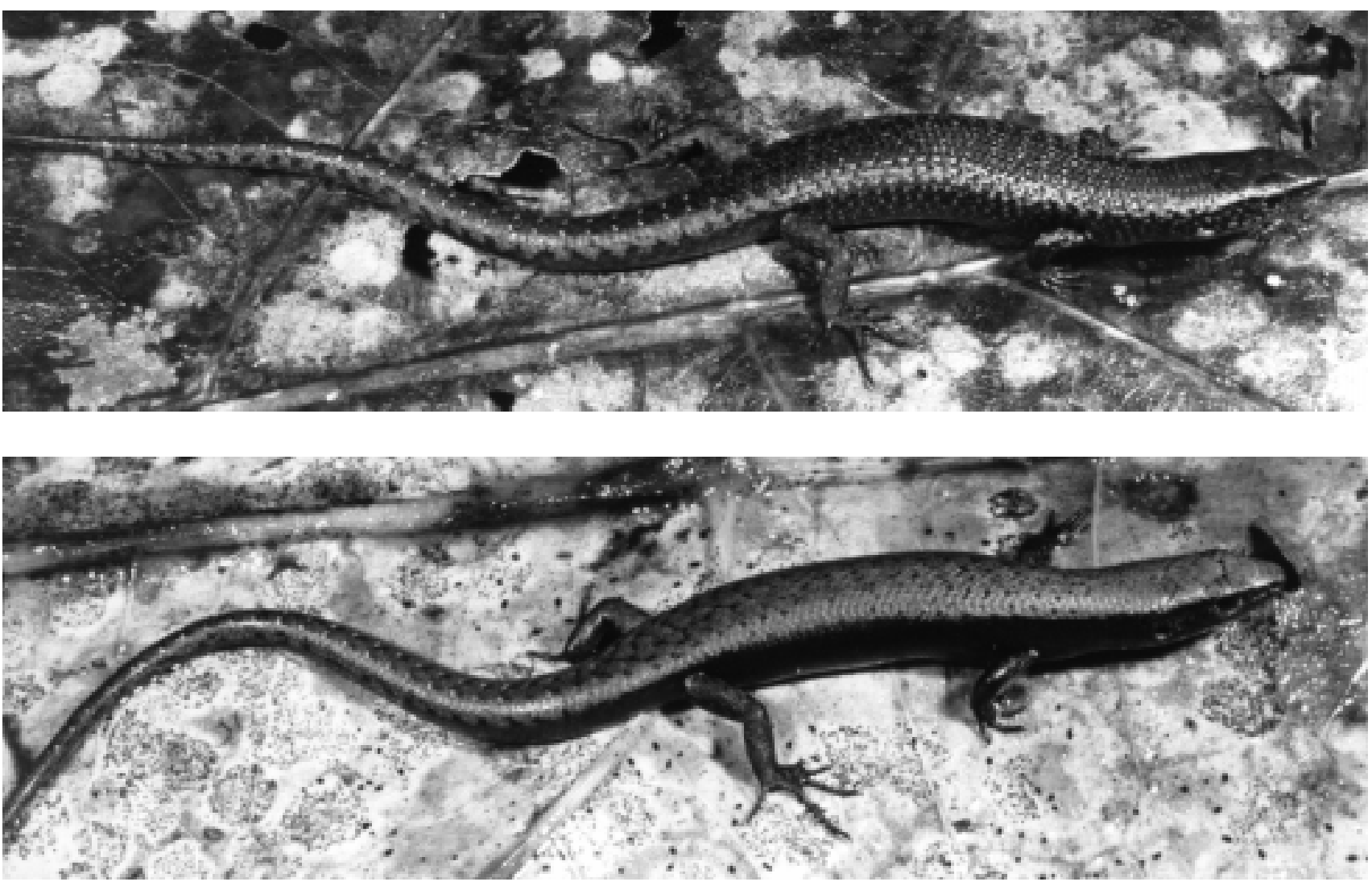

Figure 6. Caledoniscincus aquilonius male (upper) and female (lower) from Mt Panié.

heterozygotes for the Gpi locus were present. While some specimens from each of these samples are regarded as conspecific with the type series, the genetic variation observed in the remaining specimens could be due to the presence of a second cryptic species. For this reason the Kavaatch and Koumac samples are not included in the type series. Several other samples are also here regarded as conspecific with $C$. aquilonius but were collected subsequent to the electrophoretic study and lack genetic data for inclusion in the type series. These samples represent populations from: the upper reaches of the Hienghène Valley; the Roches d'Ouaième near Ouinguip; and main range between Kone and Poindimié.

The sample from Koumac Caves on the northwest coast (eight specimens included in the electrophoretic study) showed no significant differences in scalation to the type series of $C$. aquilonius from the northeast ranges. Variation in colour and pattern of adult male $C$. aquilonius from Koumac is however more difficult to assess as only a single subadult and single adult male were collected.

Two collections made in the northeast of the island from the upper reaches of the Hienghène Valley and Roches d'Ouaième between Hienghène and the Ouaïème River were made subsequent to the electrophoretic analysis. These specimens fall within the range of variation in scalation for C. aquilonius, and most adult males have the broad pale laterodorsal margin typical of this species; hence they are here assigned to $C$. aquilonius.
A collection of specimens made at mid-altitude on the main range between Kone and Poindimié, is most similar to $C$. aquilonius but differs in having generally fewer midbody scale rows $(\bar{x}=30$ vs 32$)$ than the type series and the dorsolateral margin variably patterned. The dorsal coloration of the majority of adult males from this population is uniformly mid to dark brown with numerous, fine, pale and dark flecks, only a few individuals having what could be interpreted as a pale dorsolateral margin.

Two adult male Caledoniscincus from Mt Ignambi approximately $20 \mathrm{~km}$ north of Mt Panié (NHMB 7325 collected by Roux and Sarasin in 1911 and a single recently collected specimen AMS R152223) are similar in colour and pattern to C. aquilonius from Mt Panié, but differ in being larger (52-55 $\mathrm{mm} \mathrm{SVL}$ ), having more dorsal scale rows (60), and coming from a much higher altitude $(1,000$ $\mathrm{m} v$ s maximum $690 \mathrm{~m}$ for C. aquilonius on Mt Panié). It is unclear whether these specimens represent another undescribed species or variation in both scalation and altitudinal limits not previously observed in C. aquilonius.

Additional material. The following specimens are also assigned to C. aquilonius but not included in the type series: AMS R77864, R77894, R144205, R144214-15, R144255-56, R146364-65, R149311-13, R149319-23, 149342-43, R149961-62, R149965, Mt Panié; CAS 182062, CAS 198713 Tao, 20³3'S 164²8'E; AMS R77809, R77812, R138513 R144249, R144252-53 Kavaatch Forestry Camp (abandoned), 2042"S 16450'E; AMS R144296- 
97, R144259, R146338-341 Koumac Caves, approximately 9 km E of Koumac, $20^{\circ} 33^{\prime} \mathrm{S} 164^{\circ} 21^{\prime} \mathrm{E}$; AMS R150706, R150709-20 $39.6 \mathrm{~km} \mathrm{~W}$ of Hienghène on Ouyaguette road, 20.40'S 164.42'E; AMS R151346-47 vicinity of Ouinguip, $20^{\circ} 38^{\prime} \mathrm{S} 164^{\circ} 51^{\prime} \mathrm{E}$; AMS R150672-83, R150691-92 $47.2 \mathrm{~km}$ from Kone turnoff on road to east coast, $20^{\circ} 54^{\prime} \mathrm{S} 165^{\circ} 07^{\prime} \mathrm{E}$.

\section{Caledoniscincus terma n.sp.}

Figs. 5, 7

Type material. HoLOTYPE: AMS R146320 Mt Mandjélia, $10.3 \mathrm{~km}$ E Tade River crossing, New Caledonia, 20²4'S $164^{\circ} 30^{\prime} \mathrm{E}$ (R. Sadlier and A. Bauer, 4.iii.1995). PARATYPES: AMS R146312-14, R146316-19, R146321 same location as holotype; AMS R146344-46, MNHP 1997.3329 (formerly AMS R146315) Mt Mandjélia, $15 \mathrm{~m}$ asl below summit, 20²3'S 164³1'E 4/1/1995; MNHP 1997.3330 (formerly AMS R146348) Mt Mandjélia, 20²4'S 164³1'E.

Etymology. The species name is from the Latin terma, for end, alluding to the position of the type locality for this species at the northern end of the northeast ranges.

Diagnosis. Caledoniscincus terma can be distinguished from the other species of Caledoniscincus by the following combination of characters: $(a)$ moderately small size 41$50 \mathrm{~mm}$ SVL; $(b)$ tail relatively short, on average only 1.36 times longer than body; $(c)$ midbody scales in 32-34 rows; $(d)$ paravertebral scales in 55-63 rows; $(e)$ postsacral vertebrae 37-38; $(f)$ dorsal colour pattern of adult males featuring a pale vertebral stripe; lateral surface without a pale midlateral stripe; $(g)$ rostral shield with a dark midrostral streak; $(h)$ adult males with a yellow flush to the ventral surface in life.

Description. The description is based on a series of 14 specimens (4 males and 10 females) collected at the type location and includes specimens used in the electrophoresis study.

Measurements. Adult size 41-50 mm SVL; distance from axilla to groin $52.4-60.5 \%$ of SVL $(\overline{\mathrm{x}}=56.3, \mathrm{n}=14)$; distance from forelimb to snout $34.1-40.1 \%$ of SVL ( $\bar{x}=$ $38.0, \mathrm{n}=14)$; hindlimb length $31.3-30.0 \%$ of SVL $(\overline{\mathrm{x}}=35.1$, $\mathrm{n}=14)$; tail length $131.1-140.5 \%$ of $\operatorname{SVL}(\overline{\mathrm{x}}=135.8, \mathrm{n}=2)$.

Scalation. Midbody scales in $32-34$ rows $(\overline{\mathrm{x}}=32.4$, SD $=0.85, \mathrm{n}=14)$; paravertebral scales in 55-63 rows $(\overline{\mathrm{x}}=$ $58.9, \mathrm{SD}=2.56, \mathrm{n}=14)$, no significant variation $(\mathrm{P}$ value $\leq 0.05)$ between males and females $(\overline{\mathrm{x}}=57.3, \mathrm{n}=4$ vs 59.6, $\left.\mathrm{n}=10, t_{12}=-1.655, \mathrm{P}=0.124\right)$; dorsal scales of fourth finger 9-10 $(\overline{\mathrm{x}}=9.4, \mathrm{SD}=0.39, \mathrm{n}=14)$; lamellae of fourth finger $12-16(\overline{\mathrm{x}}=14.4, \mathrm{SD}=1.16, \mathrm{n}=14)$; dorsal scales of fourth toe $13-15(\overline{\mathrm{x}}=13.6, \mathrm{SD}=0.66, \mathrm{n}=14)$; lamellae of fourth toe $24-27(\overline{\mathrm{x}}=25.4, \mathrm{SD}=0.99, \mathrm{n}=14)$.

Osteology. Presacral vertebrae $29-30(\overline{\mathrm{x}}=29.1, \mathrm{SD}=$ $0.26, \mathrm{n}=14)$; postsacral vertebrae $37-38(\overline{\mathrm{x}}=37.5, \mathrm{SD}=$ $0.70, \mathrm{n}=2$ ).
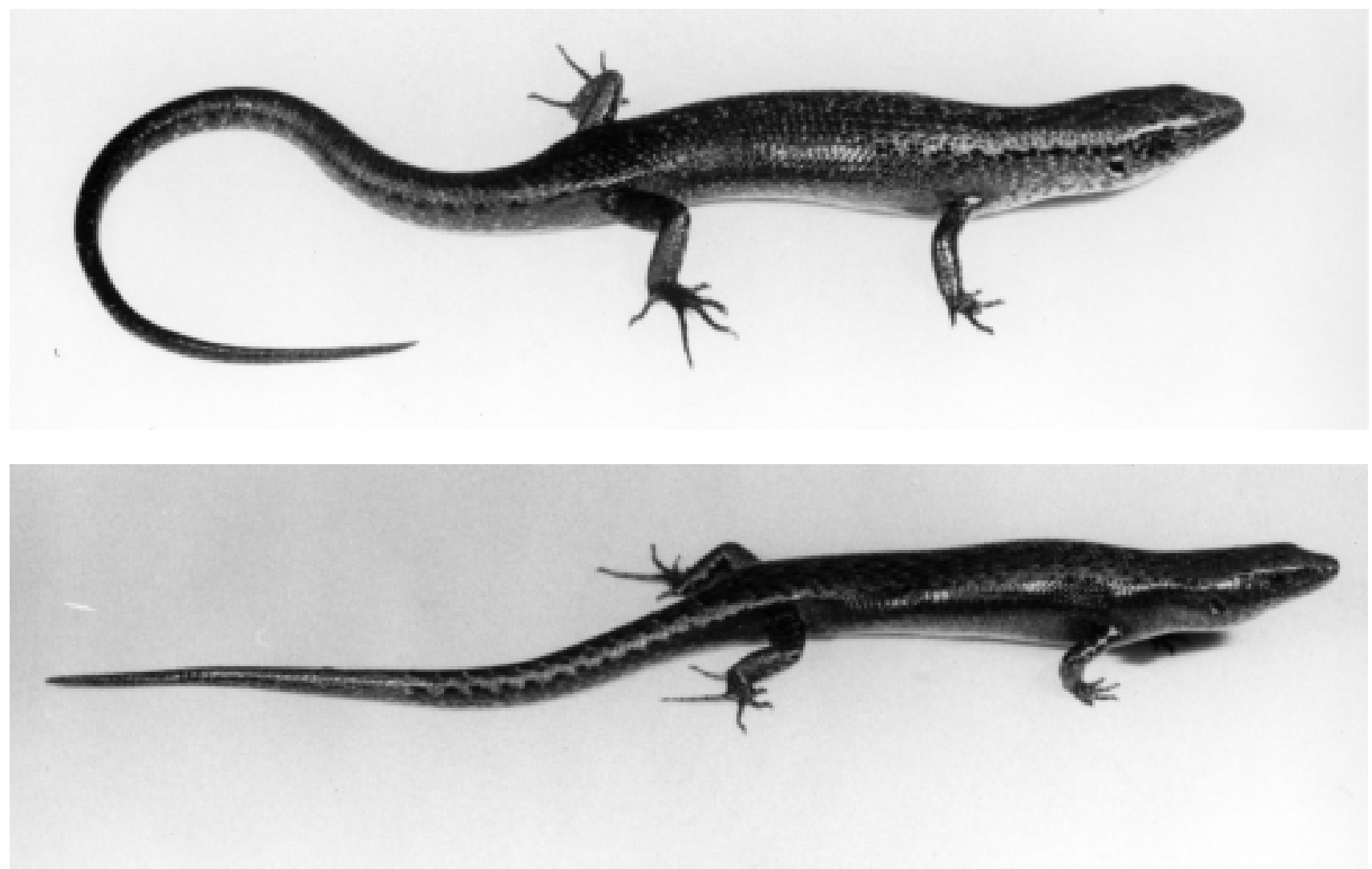

Figure 7. Caledoniscincus terma male (upper) and female (lower) from Mt Mandjélia. 
Coloration. Males: dorsal surface dark brown and with scattered, pale, dark-edged flecks; vertebral axis with a pattern of pale grey blotches forming a near continuous rough-edged stripe. Lateral surface dark brown (similar in colour to dorsal surface) and differentiated from dorsal surface anteriorly by a row of black flecks along laterodorsal edge; dorsal and lateral colorations tend to merge posterior to forelimb, dorsolateral edge rough and poorly defined. Ventral surface from level of forelimbs to basal portion of tail and underside of fore and hindlimbs yellow, continuing variably along underside of tail.

Females: dorsal surface mid brown with occasional light and numerous scattered darker flecks, larger individuals (>47 mm SVL) with a variably present series of poorly differentiated pale grey blotches along vertebral axis forming an obscure, but near continuous, rough-edged stripe down centre of back. Lateral surface dark brown-black, unmarked and with a well defined dorsolateral margin. Ventral surface from level of forelimbs to basal portion of tail and underside of fore and hindlimbs usually orange, occasionally yellow.

Details of holotype. Adult male; SVL $44 \mathrm{~mm}$; distance from axilla to groin $24 \mathrm{~mm}$; distance from forelimb to snout 18 $\mathrm{mm}$; hindlimb length $17 \mathrm{~mm}$; tail length $67 \mathrm{~mm}$, tip reproduced.

Midbody scales rows 34; paravertebral scale rows 58; dorsal scales of fourth finger $9 / 10$; lamellae of fourth finger $14 / 14$; dorsal scales of fourth toe $15 / 15$; lamellae of fourth toe $26 / 25$.

Presacral vertebrae 29.

Distribution. Known only from Mt Mandjélia, the northern most peak on the northeast ranges of New Caledonia (Fig. 5).

Biology. Restricted to mid (500 m) to high $(760 \mathrm{~m})$ altitude closed forest.

Clutch size 2-3, gravid females collected during the summer wet season (January) contained oviducal eggs (1/ $2, \mathrm{n}=2$, SVL $40-46 \mathrm{~mm}$ and $1 / 1, \mathrm{n}=2$, SVL 43-45 mm).

Additional material examined. The following specimens are assigned to $C$. terma but not included in the type series: AMS R135738-43, R135749-59, Mandjélia, at and near the summit, $20^{\circ} 24^{\prime} \mathrm{S} 164^{\circ} 32^{\prime} \mathrm{E}$.

\section{Caledoniscincus renevieri n.sp.}

Figs. 5, 8

Type material. HolOTYPE: AMS R146424 4.6 km N Col des Roussettes on Houaillou-Bourail road, New Caledonia, $21^{\circ} 24^{\prime} S 1^{\circ} 26^{\prime} E$ (R. Sadlier and A. Bauer, 8.i.1997). PARATYPES: AMS R146392-95, R146423, R146425, R146427-29, CAS 198740-43, MNHP 19997.3333 (formerly AMS R146426), MNHP 1997.3334 (formerly AMS R146430) same data as holotype; AMS R135822 4.6 $\mathrm{km}$ N Col des Roussettes on Houailou-Bourail road, $21^{\circ} 24^{\prime} \mathrm{S}$ $165^{\circ} 26^{\prime} \mathrm{E}$; AMS R77658-59, R77677 Mt Aoupinié (vicinity forestry camp $500 \mathrm{~m}$ ), $21^{\circ} 09^{\prime} \mathrm{S} 165^{\circ} 20^{\prime} \mathrm{E}$; AMS R146382-
$84 \mathrm{Mt}$ Aoupinié (1.5-2.5 km below forestry camp), $21^{\circ} 07^{\prime} \mathrm{S}$ $165^{\circ} 19^{\prime} \mathrm{E}$; AMS R146499-501 Grottes des Adio, NE of Poya, $21^{\circ} 15^{\prime} \mathrm{S} 165^{\circ} 14^{\prime} \mathrm{E}$.

Etymology. The species is named for Alain Renevier of Nouméa in recognition the generous hospitality and support he and his family have given during our field research in New Caledonia.

Diagnosis. Caledoniscincus renevieri can be distinguished from the other species of Caledoniscincus by the following combination of characters: $(a)$ moderately small size 37$51 \mathrm{~mm} \mathrm{SVL;}(b)$ tail approximately 1.4 times longer than body; (c) midbody scales in 30-32 rows; $(d)$ paravertebral scales in 51-58 rows; $(e)$ postsacral vertebrae 41-44; $(f)$ adult male dorsal colour pattern transversely oriented, occasionally with pale vertebral markings; $(g)$ lateral surface without a pale midlateral stripe; $(h)$ rostral shield with a dark midrostral streak; $(i)$ adult males with a yellow flush to the ventral surface in life.

Description. The description is based on a series of 23 specimens (12 males and 11 females) collected at the type locations and includes specimens used in the electrophoresis study.

Measurements. Adult size 37-51 mm SVL; distance from axilla to groin $51.4-60.8 \%$ of SVL $(\overline{\mathrm{x}}=55.4, \mathrm{n}=$ 23 ); distance from forelimb to snout $33.3-42.9 \%$ of SVL $(\overline{\mathrm{x}}=38.7, \mathrm{n}=23)$; hindlimb length $31.8-41.0 \%$ of SVL $(\overline{\mathrm{x}}=36.6, \mathrm{n}=23)$; tail length $127.3-154.3 \%$ of $\operatorname{SVL}(\overline{\mathrm{x}}=$ $140.2, \mathrm{n}=3)$.

Scalation. Midbody scales in $30-32$ rows $(\overline{\mathrm{x}}=30.3$, SD $=0.69, \mathrm{n}=23)$; paravertebral scales in 51-58 rows $(\overline{\mathrm{x}}=$ $53.6, \mathrm{SD}=2.02, \mathrm{n}=23)$, significant variation $(\mathrm{P}$ value $\leq 0.05)$ between males and females $(\overline{\mathrm{x}}=52.4, \mathrm{n}=12$ vs $54.9, \mathrm{n}=$ $\left.11, t_{21}=-3.730, \mathrm{P}=0.001\right)$; dorsal scales of fourth finger $8-10(\overline{\mathrm{x}}=9.0, \mathrm{SD}=0.49, \mathrm{n}=23)$; lamellae of fourth finger $13-16(\overline{\mathrm{x}}=13.6, \mathrm{SD}=0.61, \mathrm{n}=23)$; dorsal scales of fourth toe $12-13(\overline{\mathrm{x}}=12.7, \mathrm{SD}=0.47, \mathrm{n}=23)$; lamellae of fourth toe $21-29(\overline{\mathrm{x}}=24.7, \mathrm{SD}=1.40, \mathrm{n}=23)$.

Osteology. Presacral vertebrae 29-30 $(\overline{\mathrm{x}}=29.2, \mathrm{SD}=$ $0.41, \mathrm{n}=20)$; postsacral vertebrae $41-44(\overline{\mathrm{x}}=42.7, \mathrm{SD}=$ $1.53, \mathrm{n}=3)$.

Coloration. Males: dorsal surface light to mid brown with numerous pale, dark-edged flecks, dark edging of pale markings tending to align obliquely to form narrow, dark bars; pale markings along vertebral axis tending to align to form a near continuous rough-edged stripe in some larger individuals. Lateral surface darker than dorsal, variably with light and dark flecks; side of head and neck dark brown to black uppermost. Dorsolateral margin defined anteriorly (between eye and forelimbs) by a pale, narrow ( $<1$ scale width), dark-edged stripe, becoming obscure between fore and hindlimbs. Ventral surface moderate to pale yellow in life posterior of forelimbs, throat with an orange tinge.

Females: dorsal surface light-mid brown, variably with scattered dark flecks. Lateral surface darker than dorsal; mid to dark brown uppermost and unmarked; side of head and neck dark brown-black uppermost in larger individuals (>47 mm SVL). Dorsolateral margin defined anteriorly 

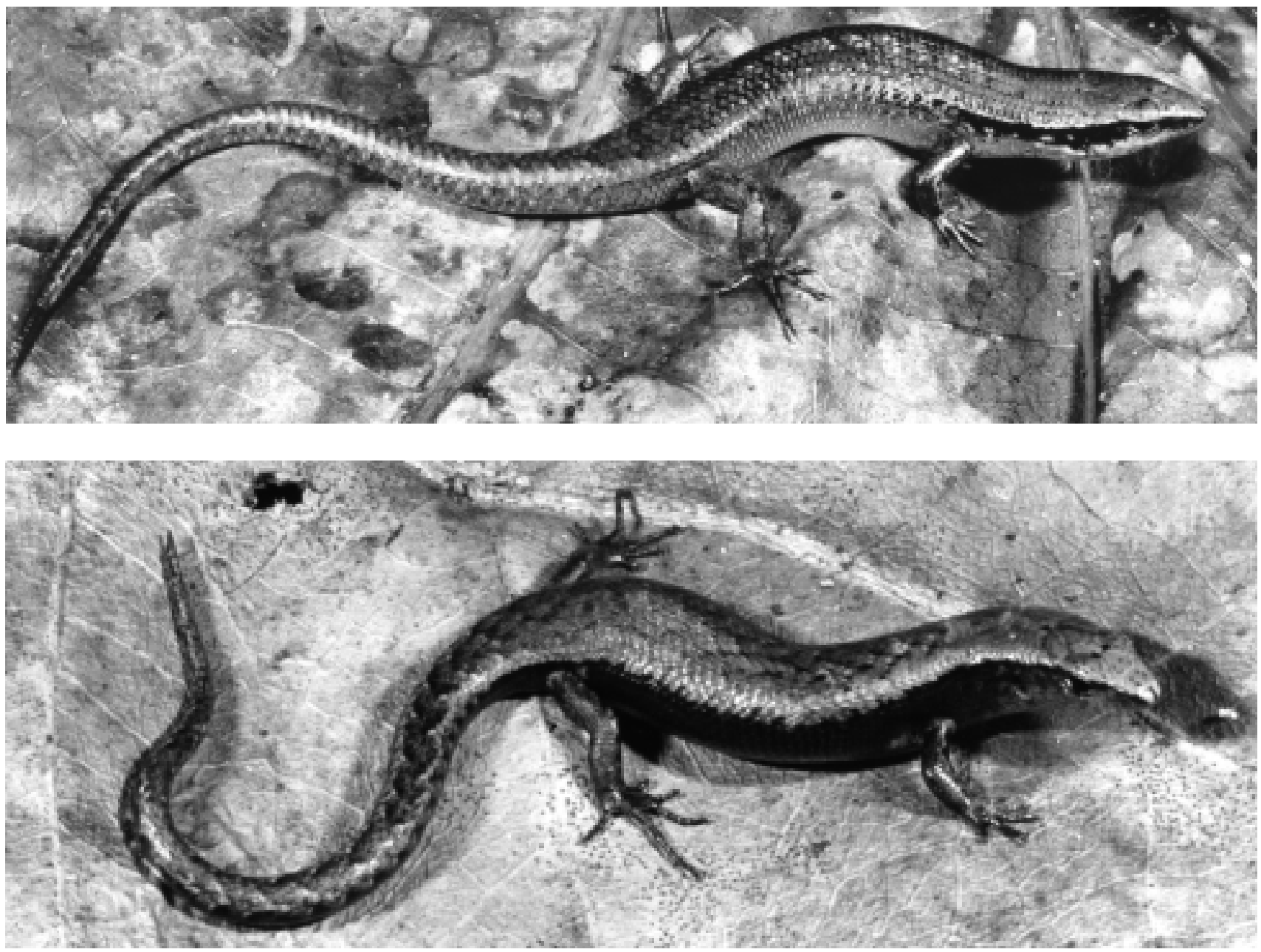

Figure 8. Caledoniscincus renevieri male (upper) and female (lower) from Col des Roussettes.

(between eye and forelimbs) by a pale, narrow ( $<1$ scale width) stripe, contrasting markedly with dark upperlateral colour between eye and forelimbs, and by the contrasting dark lateral and light upper lateral colour between fore and hindlimbs. Ventral surface either without obvious ventral colour (AMS R146394-95, R146425-26) or with a very faint yellow (AMS R146428 and R146430) or pink (AMS R146384) flush.

Details of holotype. Adult male; size $46 \mathrm{~mm}$ SVL; distance from axilla to groin $24 \mathrm{~mm}$; distance from forelimb to snout $18 \mathrm{~mm}$; hindlimb length $18 \mathrm{~mm}$; tail length $71 \mathrm{~mm}$, complete.

Midbody scale rows 30; paravertebral scale rows 53; dorsal scales of fourth finger 9/9; lamellae of fourth finger 14/14; dorsal scales of fourth toe 13/13; lamellae of fourth toe $23 / 24$.

Presacral vertebrae 29; postsacral vertebrae 41.

Distribution. Known from three locations in the central ranges at Mt Aoupinié and Grottes des Adio (western foothills of Mt Aoupinié) in the north to Col des Roussettes in the south (Fig. 5). All locations are in relatively close proximity to one another, the Adio and Mt Aoupinié locations are separated by $10 \mathrm{~km}$, and these locations are approximately 25-30 km north of Col des Roussettes.

Biology. Lowland and mid-altitude closed forests where it can be relatively abundant. On Mt Aoupinié and at Col des Roussettes it was collected in closed forest gullies and at Adio Caves in closed forest at the base of limestone outcrops.

Clutch size 2-4 (mode 2), gravid females collected during the summer wet season (January) contained oviducal eggs $(1 / 1, \mathrm{n}=5, \mathrm{SVL} 41-47 \mathrm{~mm} ; 1 / 2, \mathrm{n}=1, \mathrm{SVL} 51 \mathrm{~mm}$; and $2 /$ $2, \mathrm{n}=1$, SVL $50 \mathrm{~mm}$ ).

\section{Caledoniscincus auratus n.sp.}

Figs. 5, 9, 10

Type material. HoLOTYPE: AMS R144298 Koumac Caves, approximately $9 \mathrm{~km}$ E of Koumac, New Caledonia, 20 33 'S 164²1'E (R. Sadlier, 23-24.iv.1994). PARATYPES: AMS R144299-300, R144304, MNHN 1997.3335 (formerly 


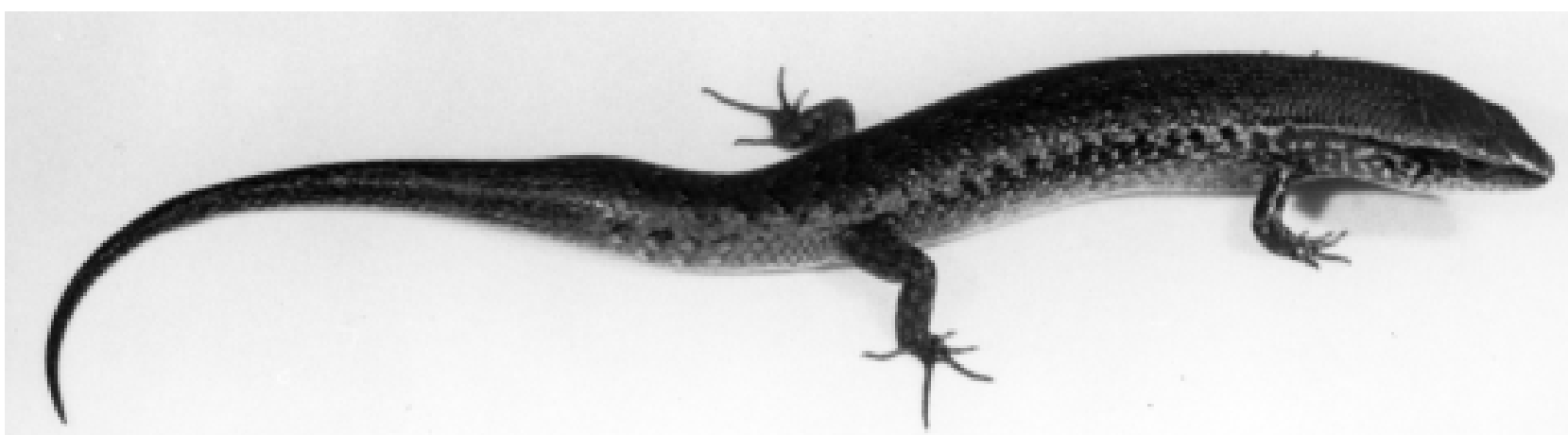

Figure 9. Caledoniscincus auratus male from Koumac Caves.

AMS R144302), MNHN 1997.3336 (formerly AMS R144303) location as for holotype; AMS R144381-82 location as for holotype.

Etymology. The species name is from the Latin auratus, for golden or ornamented with gold, and alludes to the prominent gold flecking on adult males of this species.

Diagnosis. Caledoniscincus auratus can be distinguished from the other species of Caledoniscincus by the following combination of characters: (a) moderately small size 38$51 \mathrm{~mm} \mathrm{SVL;}(b)$ tail on average 1.47 times longer than body; (c) midbody scales in 28 rows; $(d)$ paravertebral scales in 52-55 rows; $(e)$ postsacral vertebrae 43-45; $(f)$ adult male dorsal colour pattern transversely oriented and without a pale vertebral stripe; $(g)$ lateral surface without a pale midlateral stripe; $(h)$ rostral shield with a dark midrostral streak; $(i)$ adult males with a yellow flush to the ventral surface in life.

Description. The description is based on specimens collected at the type locations and includes only those specimens used in the electrophoresis.

Measurements. Adult size 38-51 mm SVL; distance from axilla to groin $52.6-56.9 \%$ of SVL $(\overline{\mathrm{x}}=55.0, \mathrm{n}=8)$; distance from forelimb to snout $37.3-41.0 \%$ of SVL $(\overline{\mathrm{x}}=39.5, \mathrm{n}=$

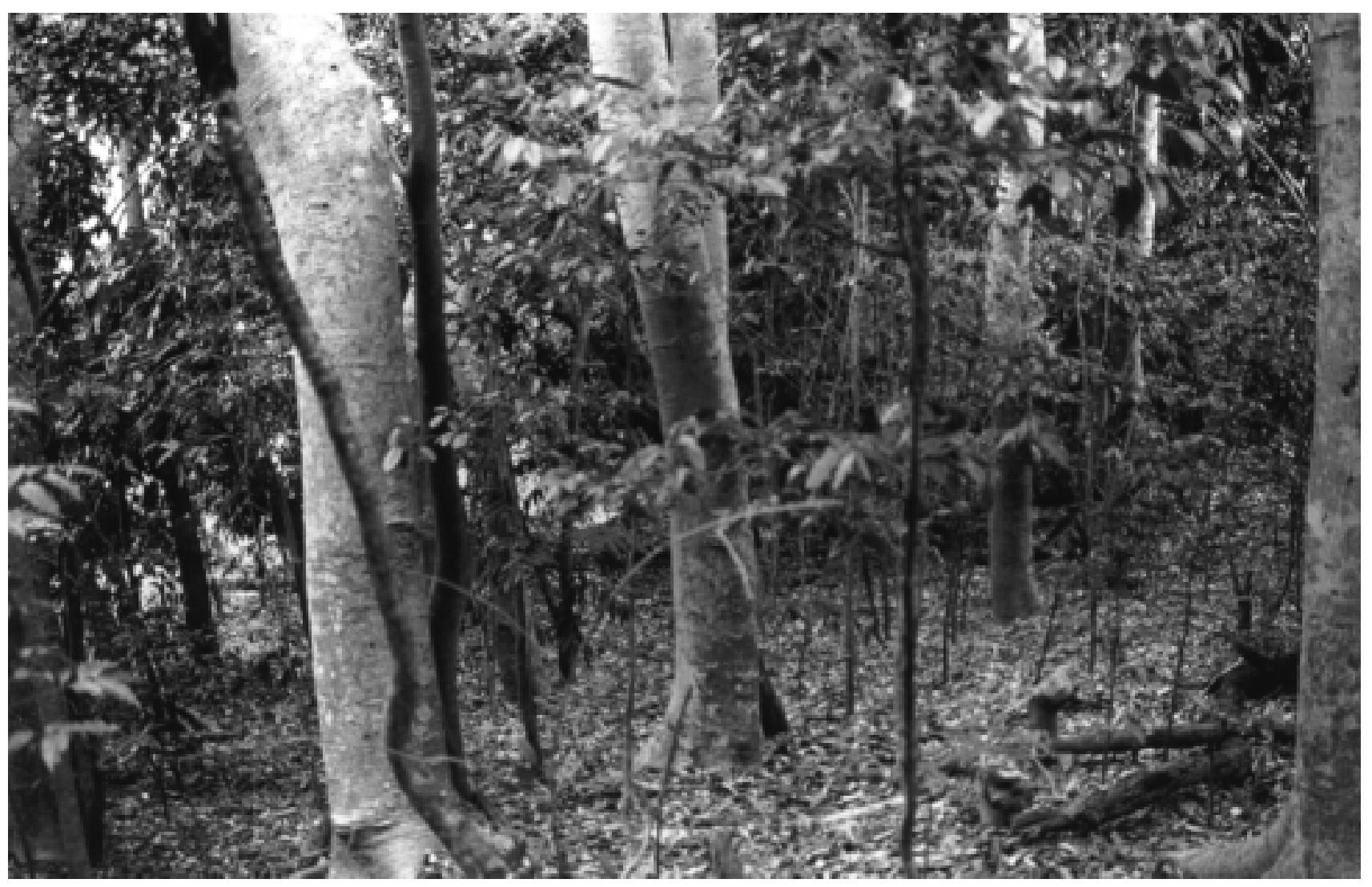

Figure 10. Closed forest habitat at Koumac Caves, near type locality of Caledoniscincus auratus. 
8); hindlimb length $31.4-39.5 \%$ of SVL $(\overline{\mathrm{x}}=37.5, \mathrm{n}=$ 8); tail length $141.0-151.3 \%$ of SVL $(\overline{\mathrm{x}}=146.8, \mathrm{n}=4)$.

Scalation. Midbody scales in 28 rows $(\mathrm{n}=8)$; paravertebral scales in 52-55 rows $(\overline{\mathrm{x}}=53.6, \mathrm{SD}=1.06$, $\mathrm{n}=8)$; dorsal scales of fourth finger $9-11(\overline{\mathrm{x}}=9.25, \mathrm{SD}=$ $0.46, \mathrm{n}=8)$; lamellae of fourth finger $12-15(\overline{\mathrm{x}}=13.75$, $\mathrm{SD}=0.87, \mathrm{n}=8)$; dorsal scales of fourth toe $13-14(\overline{\mathrm{x}}=$ $13.1, \mathrm{SD}=0.23, \mathrm{n}=8)$; lamellae of fourth toe $21-25(\overline{\mathrm{x}}=$ 22.9, $\mathrm{SD}=1.35, \mathrm{n}=8$ ).

Osteology. Presacral vertebrae $29-30(\overline{\mathrm{x}}=29.2, \mathrm{SD}=$ $0.41, \mathrm{n}=20)$; postsacral vertebrae $43-45(\overline{\mathrm{x}}=44.0, \mathrm{SD}=$ $0.82, \mathrm{n}=4)$

Coloration. Adult males: dorsal surface mid brown with a pattern of numerous pale, dark-edged spots, aligned to form a pattern of irregular and merging transverse bars (dark edging muted in smaller males 38$41 \mathrm{~mm} \mathrm{SVL}$ ); head with a few fine dark spots anteriorly. Lateral surface much lighter than dorsal, cream with a brownish wash uppermost and dark markings over most the surface; dark lateral markings largest and boldest uppermost, particularly in region between forelimb and ear opening, becoming suffused approaching the venter; laterodorsal margin between forelimb and ear opening light brown and distinct from darker lateral and dorsal colours. Ventral surface pale, with a moderate to dull yellow flush from level of forelimbs to basal portion of tail in some larger males.

Females: dorsal surface mid brown with sparse dark flecking. Lateral surface dark brown to black, uniform in colour; laterodorsal margin between forelimb and ear opening light brown and distinct from darker lateral and dorsal colours. Ventral surface pale, variably with a dull pink flush posterior of forelimbs in more mature females.

Details of holotype. Adult male; SVL $51 \mathrm{~mm}$; distance from axilla to groin $29 \mathrm{~mm}$; distance from forelimb to snout $19 \mathrm{~mm}$; hindlimb length $16 \mathrm{~mm}$; tail length $57 \mathrm{~mm}$, mostly regenerated.

Midbody scales rows 28; paravertebral scale rows 52; dorsal scales of fourth finger $9 / 9$; lamellae of fourth finger 13/14; dorsal scales of fourth toe 13/13; lamellae of fourth toe $24 / 24$.

Presacral vertebrae 29.

Distribution. Known only from Koumac Caves in the northwest of New Caledonia (Fig. 5).

Biology. Restricted to lowland closed forest (Fig. 10), resembling dry monsoon forest, adjacent to limestone outcrops at Koumac Caves.

Additional material examined. The following specimens are assigned to $C$. auratus but not included in the type series. They agree with the types in morphology but were not part of the electrophoretic analyses: AMS R144301, R146331, R146333, R144384 same location as holotype.

Comments. A single female (SVL $43 \mathrm{~mm}$ ) not included in the type series and collected during the summer wet season (January) had 3 oviducal eggs (1/2).

\section{Caledoniscincus chazeaui n.sp.}

Figs. 5, 11-13

Type material. HOLOTYPE: AMS R138515 Koulnoué, Hienghène region, New Caledonia, $20^{\circ} 41^{\prime} 32^{\prime \prime} \mathrm{S}$ $164^{\circ} 59^{\prime} 10^{\prime \prime E}$ (R. Sadlier and A. Bauer, 26.ii.1992). PARATYPES: MNHP 1997.3337 (formerly AMS R138516), CAS 182073-74 same location as holotype.

Etymology. The species is named for Jean Chazeau of the Laboratoire de Zoologie Appliquée at ORSTOM Nouméa, in recognition of his generous support and enthusiasm for our research on New Caledonian lizards.

Diagnosis. Caledoniscincus chazeaui can be distinguished from the other species of Caledoniscincus by the following combination of characters: (a) small size 36-43 mm SVL; (b) tail approximately 1.36 times longer than body; (c) midbody scales in 28-30 rows; $(d)$ paravertebral scales in 59-61 rows; (e) postsacral vertebrae 42; $(f)$ adult dorsal colour pattern transversely oriented and without a pale vertebral stripe; $(g)$ lateral surface without a pale midlateral stripe; $(h)$ rostral shield with a dark midrostral streak.

Description. The description is based on four specimens collected at the holotype location and includes specimens used in the electrophoresis study.

Measurements. Adult size 36-43 mm SVL; distance from axilla to groin $52.8-55.8 \%$ of $\operatorname{SVL}(\bar{x}=54.6, n=4)$; distance from forelimb to snout $37.2-38.9 \%$ of SVL ( $\overline{\mathrm{x}}=37.9, \mathrm{n}=$ 4); hindlimb length $33.3-37.5 \%$ of SVL $(\bar{x}=34.8, n=4)$; tail length $136.1 \%$ of SVL $(n=1)$.

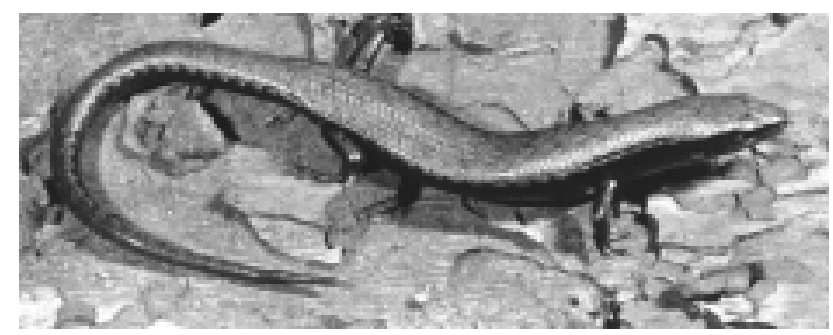

Figure 11. Caledoniscincus chazeaui from Koulnoué, Hienghène region.

Scalation. Midbody scales in 28-30 rows $(\overline{\mathrm{x}}=29.0$, SD $=1.55, \mathrm{n}=4)$; paravertebral scales in 59-61 rows $(\overline{\mathrm{x}}=59.8$, $\mathrm{SD}=0.96, \mathrm{n}=4)$; dorsal scales of fourth finger $9(\mathrm{n}=4)$; lamellae of fourth finger $12-14(\overline{\mathrm{x}}=13.4, \mathrm{SD}=0.95, \mathrm{n}=4)$; dorsal scales of fourth toe $12-13(\overline{\mathrm{x}}=12.8, \mathrm{SD}=0.5, \mathrm{n}=4)$; lamellae of fourth toe 21-23 ( $\overline{\mathrm{x}}=22.3, \mathrm{SD}=0.50, \mathrm{n}=4)$.

Osteology. Presacral vertebrae $29(\mathrm{n}=4)$; postsacral vertebrae $42(\mathrm{n}=1)$.

Coloration. The following decryption of colour and pattern is based on two adult females (AMS R138515 and MNHP 1997.3337). Dorsal surface mid brown with a pattern of numerous pale spots, dark-edged at sides, aligned to form a pattern of irregular and merging transverse bars; head with a few fine dark spots anteriorly. Lateral surface between 


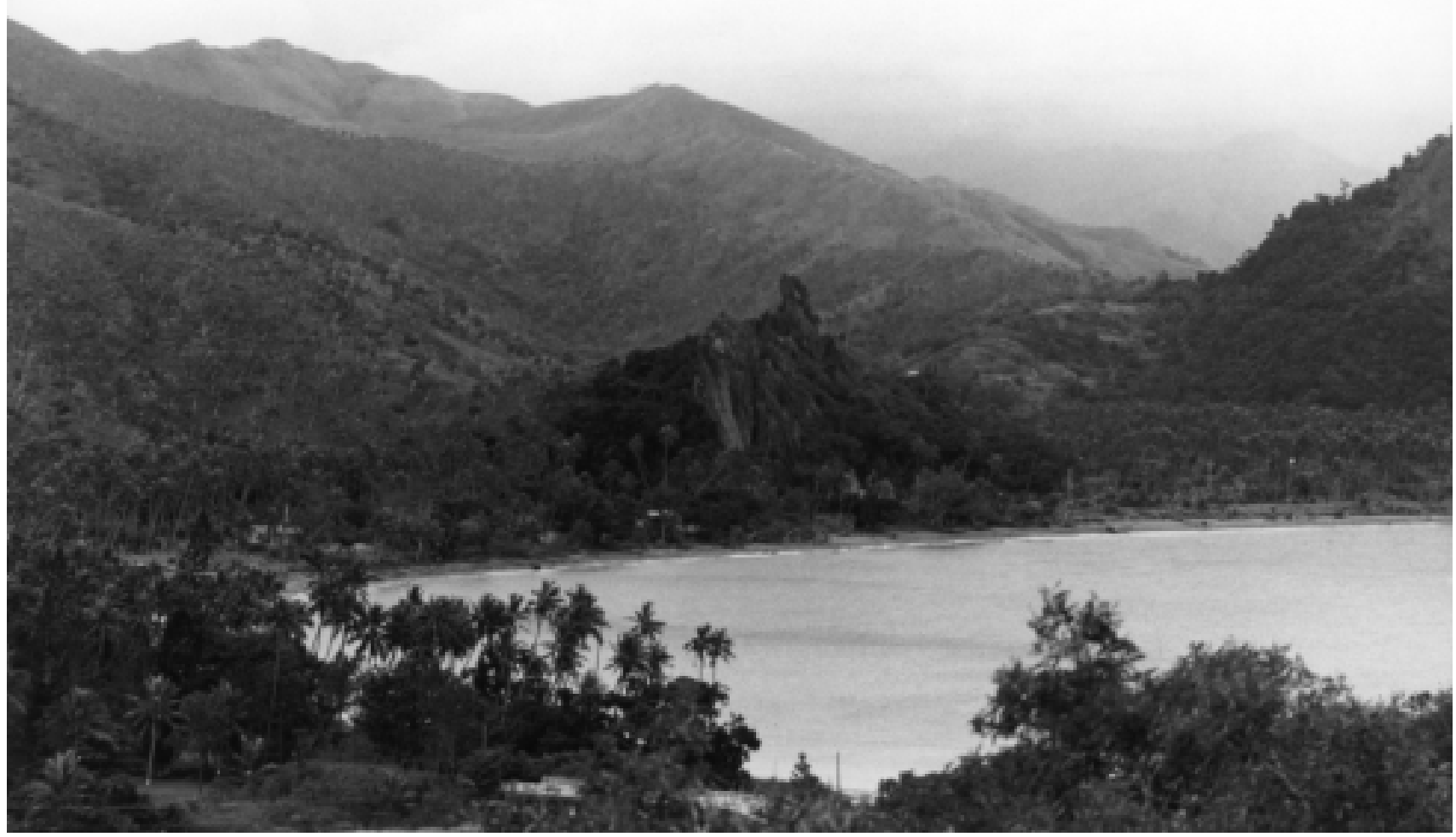

Figure 12. Isolate limestone outcrops in Hienghène region, typical habitat for Caledoniscincus chazeaui.

fore and hindlimbs brown and unmarked, similar to and merging with dorsal surface but becoming lighter approaching venter; between forelimb and ear opening with light and dark markings and either side of eye with bold dark markings; laterodorsal margin between forelimb and ear marked by a narrow, pale, dark-edged stripe, distinct from darker lateral and dorsal colours. Ventral surface pale and unmarked; colour in life unknown.

Details of holotype. Adult female; size $42 \mathrm{~mm}$ SVL; distance from axilla to groin $23 \mathrm{~mm}$; distance from forelimb to snout $16 \mathrm{~mm}$; hindlimb length $14 \mathrm{~mm}$; tail length $51 \mathrm{~mm}$, reproduced.

Midbody scales rows 28; paravertebral scale rows 59; dorsal scales of fourth finger $9 / 9$; lamellae of fourth finger 12/12; dorsal scales of fourth toe 12/12; lamellae of fourth toe $22 / 21$.

Presacral vertebrae 29.

Distribution. The type specimens were collected from a single location at Koulnoué on the northeast coast in the vicinity of Hienghène (Fig. 5). Specimens from a disjunct forest patch approximately $10 \mathrm{~km}$ south of the type location possibly represent a second location for this species; however, they are only tentatively assigned to Caledoniscincus chazeaui pending further field research.

Biology. Restricted to lowland closed forest surrounding limestone outcrops south of Hienghène (Figs. 12, 13). The forest patches are remnants and widely disjunct from one another, the intervening areas being covered with secondary growth or disturbed habitat, either through shifting cultivation, or regular burning to produce extensive areas of grassland.

Additional material examined. A series of 11 specimens (AMS R77823-29, R77832-35) collected 20 years ago from a nearby location $(14 \mathrm{~km}$ south of the Hienghène River bridge, $\left.20^{\circ} 43^{\prime} 27^{\prime \prime} \mathrm{S} 165^{\circ} 02^{\prime} 00^{\prime \prime} \mathrm{E}\right)$ are similar to specimens from the type locality in size, coloration, and habitat preferences. However, these specimens were not part of the electrophoresis study and showed significant differences in a number of scalation characters to the sample from the type locality. For these reasons they were not included in the type series of Caledoniscincus chazeaui and are here only tentatively assigned to this species.

Nine specimens from the sample collected $14 \mathrm{~km}$ south of the Hienghène River bridge showed the following counts for six variable scalation characters: midbody scales in 3032 rows $(\overline{\mathrm{x}}=30.4, \mathrm{SD}=0.88, \mathrm{n}=9)$; paravertebral scales in 60-64 rows $(\bar{x}=62.1, S D=1.36, n=9)$; dorsal scales of fourth finger $8-11(\overline{\mathrm{x}}=8.9, \mathrm{SD}=0.93, \mathrm{n}=9)$; lamellae of fourth finger $13-16(\overline{\mathrm{x}}=14.8, \mathrm{SD}=0.90, \mathrm{n}=9)$; dorsal scales of fourth toe $13-15(\overline{\mathrm{x}}=13.9, \mathrm{SD}=0.76, \mathrm{n}=9)$; lamellae of fourth toe $23-32(\overline{\mathrm{x}}=25.9, \mathrm{SD}=2.69, \mathrm{n}=8)$. For five of the six scalation characters this sample differs significantly from the type series in having: more midbody scales $\left(\overline{\mathrm{x}}=30.4\right.$ vs $\left.29, t_{11}=2.494, \mathrm{P}<0.030\right)$; more dorsal 


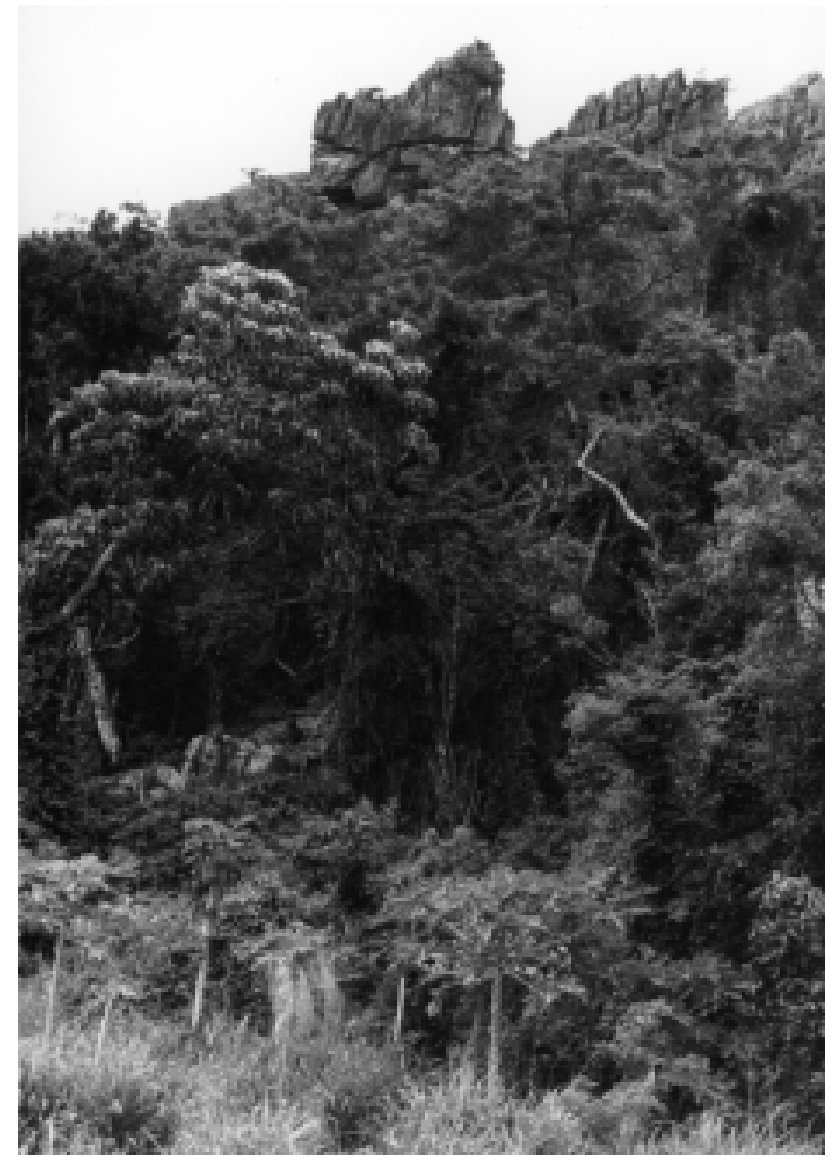

Figure 13. Closed forest growing on and around limestone outcrop in Hienghène region.

scales $\left(\overline{\mathrm{x}}=62.1\right.$ vs 59.8, $\left.t_{11}=3.103, \mathrm{P}<0.010\right)$; more finger lamellae $\left(\overline{\mathrm{x}}=14.8\right.$ vs $\left.13.4, t_{11}=2.655, \mathrm{P}<0.022\right)$; more toe scales $\left(\overline{\mathrm{x}}=13.9\right.$ vs $\left.12.8, t_{11}=2.818, \mathrm{P}<0.017\right)$; and more toe lamellae $\left(\overline{\mathrm{x}}=25.9 v s 22.3, t_{10}=2.654, \mathrm{P}<0.024\right)$.

Adult females from the series of specimens collected 14 $\mathrm{km}$ south of the Hienghène River bridge during the summer wet season (January) had yolked follicles $(1 / 2, \mathrm{n}=1, \mathrm{SVL}$ $41.5 \mathrm{~mm})$ and oviducal eggs $(1 / 2, \mathrm{n}=1$, SVL $42.5 \mathrm{~mm})$, indicating the clutch size of 3 for this population of Caledoniscincus chazeaui.

\section{Caledoniscincus cryptos n.sp.}

Figs. 5, 14, 15

Type material. HolOTYPE: AMS R135141 an adult male from $8.3 \mathrm{~km}$ from Kouaoua/Canala road intersection on La

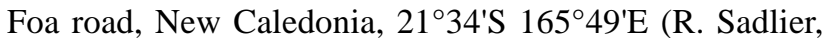
18/iii/1990).

Etymology. The species name is from the Greek cryptos, for hidden or concealed, and alludes to the recognition of this species through genetic analyses only.

Diagnosis. Caledoniscincus cryptos is recognised mainly on the following electrophoretic characteristics: $(i)$ it is homozygous (in the only available specimen) for an allele of $\operatorname{Gapdh}(A)$ which is found nowhere else in our samples; (ii) it is also homozygous for $F b p(C)$ and $G 3 p d h(A)$ which are found only as single heterozygotes in non-sympatric C. orestes or $C$. haplorhinus respectively; (iii) it has fixed differences from morphologically similar $C$. renevieri and $C$. auratus at these three loci; (iv) additional fixed differences from $C$. renevieri are found at Idhp- 1 and Pep:LA; $(v)$ an additional fixed difference from $C$. auratus is seen at $P g d h$.

Caledoniscincus cryptos can also tentatively be distinguished from most other species of Caledoniscincus by the following combination of characters: $(a)$ moderately small, $45 \mathrm{~mm}$ SVL; $(b)$ midbody scales in 30 rows; $(c)$ paravertebral scales in 51 rows; $(d)$ adult male dorsal colour pattern transversely oriented and without a pale vertebral stripe; $(e)$ lateral surface without a pale midlateral stripe; $(f)$ rostral shield with a dark midrostral streak.

Description and details of holotype. Measurements. Size $45 \mathrm{~mm} \mathrm{SVL}$; distance from axilla to groin $24 \mathrm{~mm}(53.3 \%$ of SVL); distance from forelimb to snout $19 \mathrm{~mm}$ (42.2\% of SVL); hindlimb length $18 \mathrm{~mm}$ (40.0\% of SVL); tail missing.

Scalation. Midbody scales in 30 rows; paravertebral scales 51; dorsal scales of fourth finger 9/9; lamellae of fourth finger 12/13; dorsal scales of fourth toe $12 / 13$; lamellae of fourth toe $25 / 25$.

Osteology. Presacral vertebrae 29.

Coloration. Dorsal surface mid brown with a pattern of numerous pale spots, dark-edged at the sides, and aligned to form a reticulate pattern of irregular and merging dark transverse bars; head with a few fine dark spots anteriorly. Lateral surface brown and unmarked between fore and hindlimbs, similar to and merging with dorsal surface uppermost and becoming lighter approaching the venter; dark brown to black between forelimb and ear opening, dark markings boldest either side of eye between ear opening and snout; laterodorsal margin between forelimb and ear opening a narrow, pale, stripe distinct from darker lateral and dorsal colours.

Ventral surface pale, unmarked; colour in life unknown.

Distribution. Known only from a single site in the ranges near Col d'Amieu in the central ranges of New Caledonia (Fig. 5).

Biology. Known only from mid altitude closed forest (Fig. 15).

\section{Comparison of species}

Electrophoretic results. Fixed differences in sympatry support the recognition of the new taxa described here as distinct species from Caledoniscincus austrocaledonicus and $C$. haplorhinus where they occur at the same locality. There are three genetically distinct species found at Koumac (C. aquilonius, C. auratus and C. haplorhinus). There are a minimum of three fixed differences between any pair of these species at this site, indicating reproductive isolation. There are four fixed differences between $C$. terma and $C$. austrocaledonicus at Mandjélia (the rare IDHP-2 C 
allozyme in the latter species not being found there). All three populations of $C$. renevieri occur in sympatry with $C$. austrocaledonicus, there are five fixed and two nearly fixed differences between the taxa at these localities. Caledoniscincus chazeaui has ten and C. cryptos eight fixed differences from sympatric $C$. austrocaledonicus in the single localities represented in the electrophoretic study.

Otherwise the species of Caledoniscincus described here are largely allopatric sibling species restricted to closed forest in the central and northern regions of the island. The genetic data for these species indicate that $C$. renevier $+C$. auratus $+C$. cryptos form a discrete group. These species are similar in size, adult male coloration, and ventral colour in both sexes ( $C$. renevieri $+C$. auratus), and as such may ultimately be recognised as a natural group. Conversely $C$. aquilonius $+C$. terma and $C$. chazeaui are part of a larger group that also includes $C$. austrocaledonicus, $C$. haplorhinus, and C. orestes. No unifying morphological trait that might be indicative of close relationship has been identified in the species in this group.

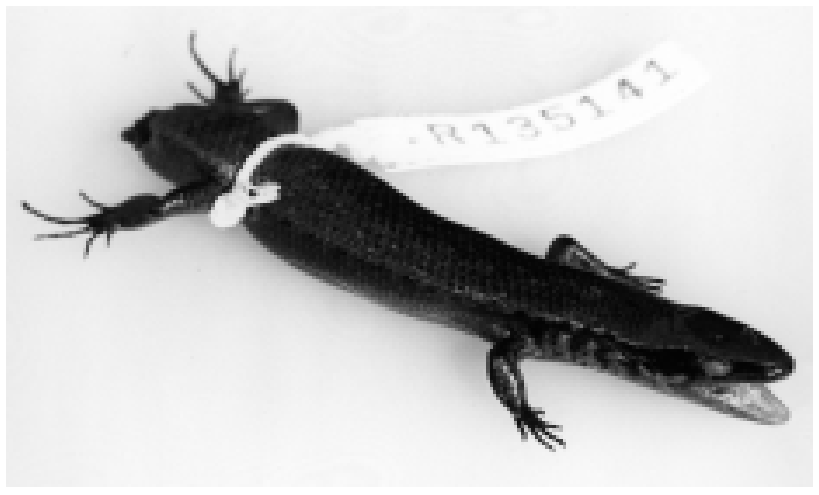

Figure 14. Caledoniscincus cryptos holotype (AMS R135141).

The genetic distance (0.12) separating morphospecies Caledoniscincus aquilonius and $C$. terma is relatively small. This is a low value for distances between species in the Scincidae (Kim et al., 1978; Milton et al., 1983; Murphy et al., 1983; Daugherty et al., 1990; Sadlier et al., 1993). Caledoniscincus aquilonius and C. terma are, however, clearly distinct on a number of morphological characteristics, emphasising that genetic distance alone should not be used as a criterion of species level differentiation.

Morphology. Table 3 shows the range of variation for those mensural, scalation, and coloration characteristics used in the diagnoses in the species accounts, and provides a ready cross-comparison of these key features between all species of Caledoniscincus.

Caledoniscincus austrocaledonicus and Caledoniscincus haplorhinus are the two most widespread species dealt with here, they are sympatric at a number of locations on New Caledonia, its satellite islands, and the Loyalty Islands. In the south of the main island, Isle des Pins, and Loyalty Islands, C. austrocaledonicus lacks a white midlateral stripe, this will readily distinguish it from regionally sympatric $C$. haplorhinus. In the northern and central regions of the main island C. austrocaledonicus and C. haplorhinus are similar in size, scalation, and certain aspects of coloration, most notably both have a pale midlateral stripe. Samples of either sex in these regions can be distinguished by the expression and positioning of the white midlateral stripe at the ear opening as outlined in the diagnosis of C. austrocaledonicus.

The six new species described, Caledoniscincus aquilonius, C. terma, C. renevieri, C. auratus, C. cryptos, and $C$. chazeaui, can be distinguished from the other species in the genus as follows:

Caledoniscincus festivus is larger in adult size, has more paravertebral scale rows (similar range for C. chazeaui), and more postsacral vertebrae. Adult male $C$. festivus can be further distinguished from adult male $C$. aquilonius by ventral colour (yellow vs orange).

Caledoniscincus atropunctatus lacks the dark midrostral streak present in all these species, and has more postsacral vertebrae. Caledoniscincus atropunctatus can be further distinguished from adult male $C$. aquilonius by ventral colour (yellow $v s$ orange).

Caledoniscincus orestes is larger in adult size, has a pale vertebral stripe in adult males (present also in C. terma and some $C$. renevieri), and more postsacral vertebrae. Adult male $C$. orestes can be further distinguished from adult male

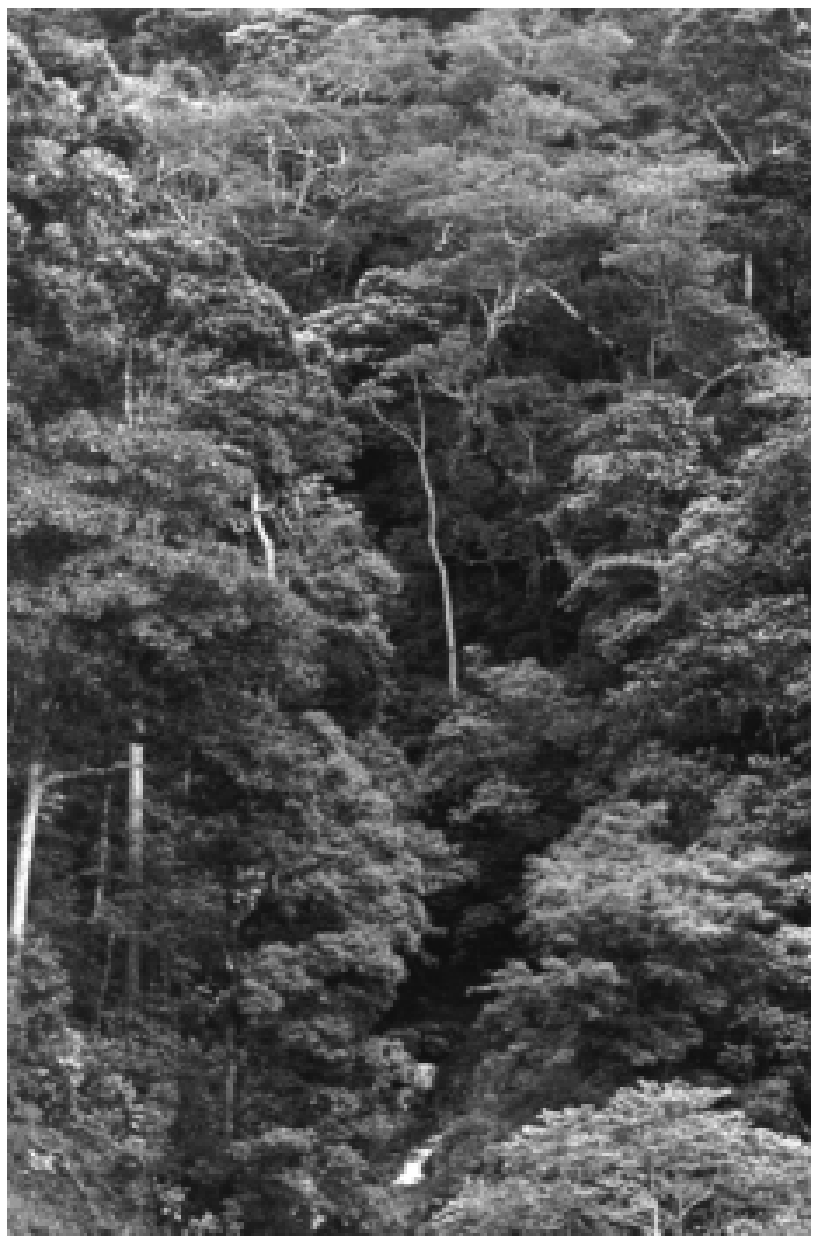

Figure 15. Typical closed forest habitat in gully near type locality of Caledoniscincus cryptos. 
C. terma, C. renevieri, and C. auratus by ventral colour (orange $v s$ yellow).

Caledoniscincus austrocaledonicus has a pale vertebral stripe in adult males (present also in C. terma and some $C$. renevieri). Adult male $C$. austrocaledonicus are further distinguished from adult male $C$. terma, C. renevieri, and $C$. auratus by ventral colour (orange vs yellow). Caledoniscincus austrocaledonicus (northern and central populations) can also be further distinguished by the presence of a pale midlateral stripe in both sexes.

Caledoniscincus haplorhinus has a pale vertebral stripe in adult males (present also in $C$. terma and some $C$. renevieri), a pale midlateral stripe in both sexes, and more postsacral vertebrae.

Caledoniscincus aquilonius, C. terma, C. renevieri, $C$. auratus, $C$. cryptos, and $C$. chazeaui are generally all most similar to one another in scalation, osteology, and to a lesser degree adult male coloration. Significant differences in morphology between these species (except $C$. cryptos) are given below as pairwise comparisons.

Caledoniscincus aquilonius can be distinguished from C. terma by: having fewer dorsal scale rows $(\overline{\mathrm{x}}=55.8 \mathrm{vs}$ $\left.58.9, t_{27}=-3.939, \mathrm{P}<0.001\right)$, a longer tail $(\overline{\mathrm{x}}=154.6 v s$ $135.8 \% \mathrm{SVL})$ and more postsacral vertebrae $(\overline{\mathrm{x}}=43.5 \mathrm{vs}$ 37.5 ), lacking a pale vertebral stripe (adult $C$. terma have a pale vertebral stripe, most obvious in males), and adult male ventral colour (orange vs yellow).

Caledoniscincus aquilonius can be distinguished from C. renevieri by: having more midbody scale rows $(\overline{\mathrm{x}}=32.2$ vs $\left.30.3, t_{36}=6.768, \mathrm{P}<0.001\right)$, more dorsal scale rows in males $\left(\overline{\mathrm{X}}=55.3\right.$ vs 52.4, $\left.t_{18}=4.892, \mathrm{P}<0.001\right)$, more fourth finger lamellae $\left(\overline{\mathrm{x}}=14.4\right.$ vs $\left.13.6, t_{36}=3.975, \mathrm{P}<0.001\right)$, and adult male ventral colour (orange $v s$ yellow).

Caledoniscincus aquilonius can be distinguished from C. auratus by: having more midbody scale rows $(\overline{\mathrm{x}}=32.2$ $v s$ 28.0), more fourth toe lamellae $\left(\overline{\mathrm{x}}=25.2 \mathrm{vs} 22.9, t_{20}=\right.$ $4.224, \mathrm{P}<0.001$ ), and adult male ventral colour (orange vs yellow).

Caledoniscincus aquilonius can be distinguished from C. chazeaui by: having more midbody scale rows $(\overline{\mathrm{x}}=32.2$ vs 29.0, $\left.t_{17}=5.191, \mathrm{P}<0.001\right)$; fewer dorsal scale rows $(\overline{\mathrm{x}}=$ 55.8 vs $\left.59.8, t_{17}=-5.512, \mathrm{P}<0.001\right)$; and more fourth toe lamellae $\left(\overline{\mathrm{x}}=25.2\right.$ vs $\left.22.3, t_{16}=4.984, \mathrm{P}<0.001\right)$.

Caledoniscincus terma can be distinguished from $C$. renevieri by: having more midbody scale rows $(\overline{\mathrm{x}}=32.3$ vs $\left.30.4, t_{22}=4.106, \mathrm{P}<0.001\right)$, more dorsal scale rows in both males $\left(\overline{\mathrm{x}}=57.3\right.$ vs $\left.52.4, t_{14}=6.183, \mathrm{P}<0.001\right)$ and females $\left(\overline{\mathrm{x}}=59.6\right.$ vs 54.9, $\left.t_{19}=4.744, \mathrm{P}<0.001\right)$, a shorter tail $(\overline{\mathrm{x}}=136.3$ vs $140.2 \% \mathrm{SVL})$ with fewer postsacral vertebrae $(\overline{\mathrm{x}}=37.5$ vs 42.7$)$, and to a lesser extent in adult male dorsal coloration (pale vertebral stripe present $v s$ usually absent in $C$. renevieri).

Caledoniscincus terma can be distinguished from $C$. auratus by: having more midbody scale rows $(\overline{\mathrm{x}}=32.4$ vs 28.0), more dorsal scale rows $\left(\overline{\mathrm{x}}=58.9\right.$ vs 53.6, $t_{20}=$ 5.555, $\mathrm{P}<0.001)$, more fourth toe lamellae $(\overline{\mathrm{x}}=25.4 \mathrm{vs}$ $\left.22.9, t_{20}=4.841, \mathrm{P}<0.001\right)$, a shorter tail $(\overline{\mathrm{x}}=136.3 v s$ $146.8 \%$ SVL) with fewer postsacral vertebrae $(\overline{\mathrm{x}}=37.5$ vs 44.0), and adult male dorsal coloration (pale vertebral stripe present $v s$ absent in C. auratus).
Caledoniscincus terma can be distinguished from $C$. chazeaui by: having more midbody scale rows $(\overline{\mathrm{x}}=32.4 \mathrm{vs}$ $\left.29.0, t_{16}=6.601, \mathrm{P}<0.001\right)$, more fourth toe lamellae $(\overline{\mathrm{x}}=$ 25.4 vs $\left.22.3, t_{16}=5.974, \mathrm{P}<0.001\right)$, fewer postsacral vertebrae $(\overline{\mathrm{x}}=37.5$ vs 42.0$)$, and adult male dorsal coloration (pale vertebral stripe present $v s$ absent in $C$. chazeaui).

Caledoniscincus renevieri can be distinguished from $C$. auratus by: having more midbody scale rows (30-32 vs 28), otherwise in scalation and adult male colour $C$. renevieri is most similar to $C$. auratus from Koumac.

Caledoniscincus renevieri can be distinguished from the type series of $C$. chazeaui by: having fewer dorsal scale rows $\left(\overline{\mathrm{x}}=53.6 v s 59.8, t_{25}=-5.902, \mathrm{P}<0.001\right)$.

Caledoniscincus auratus can be distinguished from $C$. chazeaui by: having fewer dorsal scale rows $(\overline{\mathrm{x}}=53.6 \mathrm{vs}$ 59.8, $\left.t_{10}=-9.703, \mathrm{P}<0.001\right)$.

Caledoniscincus cryptos can be distinguished from adult male $C$. aquilonius by lacking a broad pale laterodorsal margin and from $C$. terma by lacking a pale vertebral stripe. Caledoniscincus cryptos is most similar in overall appearance to $C$. renevieri and $C$. auratus in having a reticulate patterned dorsal surface (except some $C$. renevieri which have pale vertebral markings). Although no meaningful comparison of scalation can be made between $C$. cryptos and either $C$. renevieri or $C$. auratus, the values for $C$. cryptos generally fall within a single standard deviation from the mean for all scalation characters of both species.

\section{Discussion}

The results presented here have doubled the known number of species in the genus Caledoniscincus to 11. Relationships between the three isolated populations of $C$. orestes have yet to be investigated and may yield further cryptic species in the complex. Such a significant increase in diversity in the genus was unexpected on the basis of existing collections prior to 1990. Only a few of the taxa described here were represented in museum collections prior this date, and then generally only as a small number of "anomalous" specimens in particular collections. The increase in species diversity has resulted from extensive field research over the past eight years that has targeted these "anomalous" specimens and the opportunity to collect in areas not previously investigated.

The results in this paper have several biogeographical implications. The distinction between northern and southern herpetofaunas previously identified (Bauer \& Sadlier, 1993) has predominantly been based on specific and generic endemism in the extensive ultramafic block that covers much of the southern third of the island. Caledoniscincus now shows extensive speciation north of the southern ultramafic block involving a complex of largely allopatric endemics. The presence of sister species of Tropidoscincus in the north (T. variabilis) and south (as defined by the extensive southern ultramafic block-T. rohssii) also reflect the distinction between northern and southern herpetofaunas, and is similar in distribution to the variation in coloration seen in the widespread species $C$. austrocaledonicus. The northeastern ranges have also been 
identified as a significant area of endemism for lizards (Bauer \& Sadlier, 1993). The description of C. terma from Mt Mandjélia increases the number of species endemic to this region to four (the scincid lizards $C$. terma and an undescribed Nannoscincus, and the gekkonid lizards Bavayia ornata and Bavayia validiclavis). The results of our research indicate that the distribution patterns of the forest-restricted species described in this paper may reflect finer scale biogeographic regions across the central and northern regions of the island than previous studies have indicated. Further studies on widespread lizard taxa are required to see if similar distribution patterns occur.

Despite extensive field research by the authors in New Caledonia over the past eight years most of the new taxa described here are still only known from a few locations. Further field research is required to delimit accurately the distributions of these species.

\section{Conservation status}

The conservation status of the species described in this paper are assessed below and follows Bauer \& Sadlier (1993) in utilising a combination of known sites to assess distribution, average number of records per site as an indication of relative abundance, and known threats to assess vulnerability. The species are then categorised as per the current IUCN (1996) criteria where appropriate.

Caledoniscincus austrocaledonicus and C. haplorhinus are widespread and common species, neither are considered threatened and are not discussed further.

Of the six closed forest dependent species described here Caledoniscincus aquilonius and $C$. renevieri are the least restricted in distribution. Caledoniscincus aquilonius is likely to be the most widespread of the six species described here. Aside from the type location at Mt Panié it is known from four scattered localities in the far northeast ranges from near sea level to $670 \mathrm{~m}$ altitude, and in this region is likely to occur where suitable closed forest habitat is present. Populations of $C$. aquilonius in this region are relatively secure although lowland populations are likely to be threatened by loss of habitat as a result of clearing for agriculture and the impact of fire on forest margins. Extralimital populations of Caledoniscincus aquilonius are known from Koumac Caves on the west coast and the ranges west of Poindimié. The conservation status of these extralimital populations is difficult to assess until more data on the species distribution are available, particularly in the south and far north of the species range. The population of C. aquilonius from Koumac Caves is considered the most vulnerable. It is known only from the seasonally dry closed forests at Koumac Caves where remnant closed forest at the edge of the limestone outcrops is threatened by clearing for agriculture, degradation to the forest understorey and litter layer by stray cattle from adjacent farms, and fire. Because of its isolated nature and the threats posed by human activities the Koumac population of $C$. aquilonius could be regarded as potentially endangered. Research to determine the distinctiveness of this population is required before its conservation significance can be assessed under the current IUCN (1996) classification system.
Caledoniscincus renevieri is known from three sites in general proximity to one another in the central ranges from low to mid altitude, and in this region is likely to occur where there is suitable closed forest habitat. Populations of C. renevieri in this region are relatively secure although, like $C$. aquilonius, lowland populations are likely to be threatened by loss of habitat due to clearing for agriculture and fire burning the forest margins. The impact of such activities is most clearly seen at Adio Caves where closed forest habitat has been cleared to the edge of the outcropping limestone.

It is likely that with further field research both $C$. aquilonius and $C$. renevieri will become known from more localities, and both species will prove to be both moderately widespread and secure within the discrete regions in which they occur.

Two species, Caledoniscincus auratus and C. chazeaui are very restricted in distribution. Both are known to be, or have been, generally common where they occur, but are likely to be adversely affected by habitat disturbance.

Caledoniscincus auratus is known with certainty only from the seasonally dry closed forests at Koumac Caves. At this locality, closed forest at the edge of the limestone outcrops is threatened by clearing for agriculture, degradation to the forest understorey and litter layer by stray cattle from adjacent farms, and fire. Situated on the lowlands of the west coast, this forest is seasonally dry and is likely to be particularly vulnerable to the impact of fires which could alter the canopy and modify the structural and microclimate characteristics, in turn possibly adversely affecting the population of $C$. auratus. Recently a sample of three specimens containing two adult males similar in coloration to adult males from the type series of $C$. auratus was collected from near Kaala-Gomen, approximately 20 $\mathrm{km}$ south of Koumac. These specimens also were from closed forest habitat in the vicinity of limestone outcrops, and it is possible they represent the occurrence of a second population of this species in the region. Because of its apparently restricted distribution i.e. known with certainty from only a single isolated location, but possibly present at a second nearby location, $C$. auratus should at the very least be regarded as Vulnerable:D2 under the current IUCN (1996) classification system (area of occupancy $<100 \mathrm{~km}^{2}$ or number of locations $<5)$. When the threats posed by human activities at the type locality are also taken into account $C$. auratus could potentially be assessed as Endangered:B1/2c (extent of occurrence $<100 \mathrm{~km}^{2}$; known to exist at one, possibly two, locations; continuing decline in area, extent and/or quality of habitat). However, the extent of the species distribution in the region needs to be determined, and the extent of decline in both area and quality of habitat to known sites needs to established.

Caledoniscincus chazeaui is similarly restricted in distribution and habitat preference. It is known with certainty only from remnant closed forest at the edge of near-coastal limestone outcrops at Koulnoué, south of Hienghène in the northeast of the island. It was collected in 1992 in an area of closed forest habitat adjacent to limestone outcrops that bordered local gardens. Since that time the area has been revisited on two occasions (1994 and 1995) 
and $C$. chazeaui was not observed either time. These years were atypically dry and it is possible the local distribution of C. chazeaui may fluctuate with seasonal change, to be restricted to more mesic sites under suboptimal conditions. Whatever the reason for its apparent absence from this site during these latter visits, it suggests this species might be sensitive to climatic or human alteration to the habitat. Other areas of closed forest surrounding other outcrops in the region south of Hienghène are similarly developed. Samples from a nearby site tentatively assigned to this species were collected in 1978. This site was visited again in 1992 and appeared to have changed markedly in the intervening 13 years from being uninhabited to now settled with intensive subsistence agriculture carried out to the margin of the closed forest at the base of the limestone outcrops. Because of the isolated nature of the known populations and the threats posed by human activities, C. chazeaui could be regarded as Endangered:B1/2c under the current IUCN (1996) classification system (extent of occurrence $<100$ $\mathrm{km}^{2}$; one, possibly two, isolated subpopulations with a reduced probability of recolonization, if once extinct; continuing decline in area, extent and/or quality of habitat).

Caledoniscincus terma is very restricted in distribution but common where it occurs. It is not considered under any immediate threat, but because of its restricted distribution the population could be regarded as Vulnerable:D2 under the current IUCN (1996) classification system (area of occupancy $<100 \mathrm{~km}^{2}$ or number of locations $<5$ ).

Caledoniscincus cryptos is known only from a single specimen. Field research in the general area where $C$. cryptos was collected is likely to show it to be more widespread in distribution, though its apparent rarity and absence from other sites collected in the vicinity of $\mathrm{Col}$ d'Amieu is perplexing. For these reasons it regarded as Data Deficient under the current IUCN (1996) classification system.

ACKNOWLEDGMENTS. The authors thank the New Caledonian authorities for permission to collect and conduct research in New Caledonia, we particularly thank Monsieur M. Boulet, Chef du Service de l'Environnement et de la Gestion des Parcs et Réserves Province Sud, and Monsieur C. Papineau, Chef du Service F retBois-Environnement Province Nord. Logistical support and encouragement was provided by Jean Chazeau of Centre ORSTOM de Nouméa. We also thank Alain Renevier and family for their assistance and hospitality during the course of fieldwork in New Caledonia. Peter Rowland and Hervé Jourdan assisted with fieldwork. Anne Buckman performed most of the electrophoresis. Photography staff of the Australian Museum prepared the photos for publication. David McAlpine advised on the construction of species names in the descriptions. Allen Greer (AMS), Glenn Shea (Sydney University) and Ivan Ineich (MNHN) reviewed the manuscript. Jens Vindum (California Academy of Sciences) and Eugene Kramer (Naturhistorisches Museum, Basel) provided specimens for examination. To all these people we are grateful.

\section{References}

Bauer, A.M., A. Renevier \& R.A. Sadlier, 1992. Caledoniscincus austrocaledonicus (Reptilia: Scincidae) from Isle Surprise, d'Entrecasteaux Reefs, New Caledonia. Pacific Science 46(1): 86-89.

Bauer, A.M., \& R.A. Sadlier, 1993. Systematics, biogeography and conservation of the lizards of New Caledonia. Biodiversity Letters 1: 107-122.

Bavay, A., 1869. Catalogue des reptiles de la Nouvelle-Calédonie et description d'espèces nouvelles. Société Linneenne de Normandie, Mémoires 15: 137.

Borner, R., 1980. Uber neukaledonische Skinke des Leiolopisma austrocaledonicum-Komplexes. Miscellaneous Articles in Saurology 5: 1-15.

Boulenger, G.A., 1887. Catalogue of the Lizards of the British Museum. (2nd Edition). London: British Museum (Natural History).

Brygoo, E.R., 1985. Les types de Scincidés (Reptiles, Sauriens) du Muséum national d'Histoire naturelle. Zoologie, Biologie et Écologie animales 7(3): 1-126.

Colgan, D.J., \& T.F. Flannery, 1992. Biochemical systematic studies in the genus Petaurus (Marsupialia: Petauridae). Australian Journal of Zoology 40: 245-256.

Daugherty, C.H., G.B. Patterson, C.J. Thorn \& D.C. French, 1990. Differentiation of the members of the New Zealand Leiolopisma nigriplantare species complex (Lacertilia, Scincidae). Herpetological Monographs 4: 61-76.

Günther, A., 1872. LX. On some new species of reptiles and fishes collected by J. Brenchley Esq. Annals and Magazine of Natural History 10 (4th series): 418-426.

Hebert, P.D.N., \& M.J. Beaton, 1989. Methodologies for Allozyme Electrophoresis Using Cellulose Acetate. Beaumont (Texas): Helena Laboratories.

IUCN, 1996. IUCN Red List of Threatened Animals. Gland, Switzerland: IUCN.

Kim, Y.J., G.C. Gorman \& R.B. Huey, 1978. Genetic variation and differentiation in two species of the fossorial African skink Typhlosaurus (Sauria: Scincidae). Herpetologica 34: 192-194.

Kramer, E., 1979. Typenkatalog der Echsen im Naturhistorischen Museum Basel (MB), Stand 1978. Revue Suisse de Zoologie 86(1): 159-166.

Milton, D.A., J.M. Hughes \& P.B. Mather, 1983. Electrophoretic evidence for the species distinctness of Egernia modesta and E. whiteii (Lacertilia, Scincidae). Herpetologica 39: 100-105.

Murphy, R.W., W.E. Cooper, J.R. \& W.S. Richardson, 1983. Phylogenetic relationships of the North American five-lined skinks, genus Eumeces (Sauria, Scincidae). Herpetologica 39: 200-211.

Roux, J., 1913. Les reptiles de la Nouvelle-Calédonie et des îles Loyalty. In Nova Caledonia, Zoologie (vol. 1, L. 2.), eds. F. Sarasin \& J. Roux, pp. 79-160. C.W. Kreidel's Verlag: Wiesbaden.

Sadlier, R.A., 1986. A review of the scincid lizards of New Caledonia. Records of the Australian Museum 39(1): 1-66.

Sadlier, R.A., D.J. Colgan \& G.M. Shea, 1993. Taxonomy and distribution of the Australian scincid lizard Saproscincus challengeri and related species in southeastern Australia. Memoirs of the Queensland Museum 34(1): 139-158.

Swofford, D.L., \& R.B. Selander, 1981. BIOSYS-1: A FORTRAN program for the comprehensive analysis of electrophoretic data in population genetics and systematics. Journal of Heredity 72: $281-283$.

Manuscript received 19 February 1998, revised 12 January 1999 and accepted 14 January 1999.

Associate Editor: Allen E. Greer 
Table 1. Allozymic frequencies in Caledoniscincus populations. The enzyme name, abbreviation and E.C. number are given in the first row of data for each locus. Numbers in the next row indicate sample sizes. Population listings loosely follow a North to South and West to East order. Caledoniscincus aquilonius 1 is from Koumac, C. aquilonius 2 from Mt Panié and C. aquilonius 3 from Kavaatch. Caledoniscincus renevieri 1 is from Mt Aoupinié, C. renevieri 2 from Adio Caves and C. renevieri 3 from Col des Roussettes. Species' names abbreviated to first five letters.

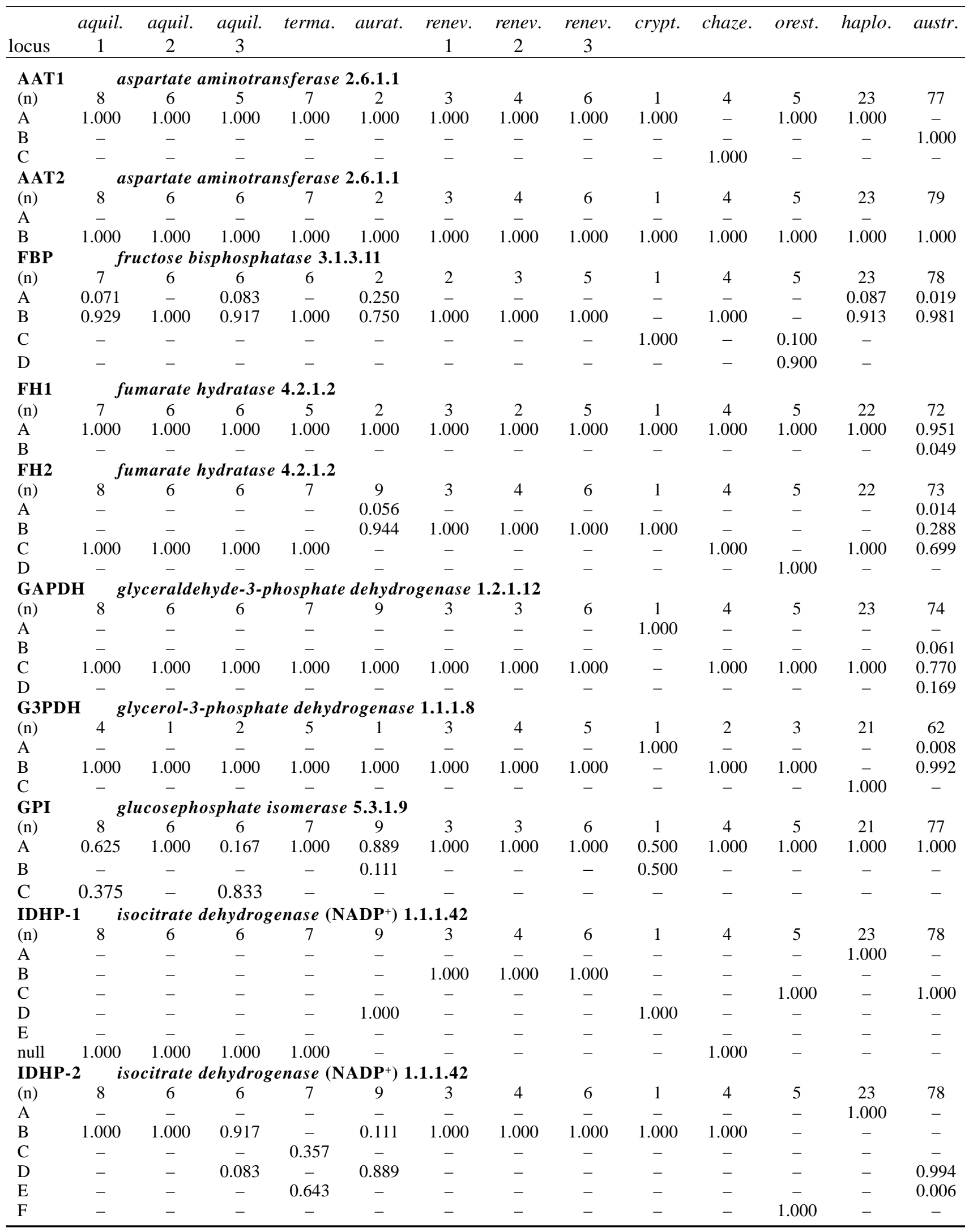


Table 1. Continued ...

aquil. aquil. aquil. terma. aurat. renev. renev. renev. crypt. chaze. orest. haplo. austr. $\begin{array}{lllllll}\text { locus } & 1 & 2 & 3 & 1 & 2 & 3\end{array}$

LDH-1 L-lactate dehydrogenase 1.1.1.27

$\begin{array}{lllllllllllll}\text { (n) } & 8 & 5 & 6 & 7 & 8 & 3 & 4 & 6 & 1 & 4 & 1 & 23\end{array}$

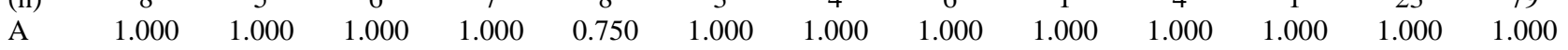

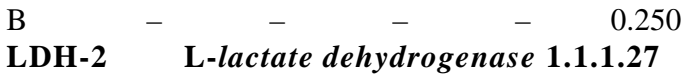

\begin{tabular}{lllllllllllll} 
(n) & 8 & 5 & 6 & 7 & 9 & 3 & 4 & 6 & 1 & 4 & 5 & 22 \\
\hline
\end{tabular}

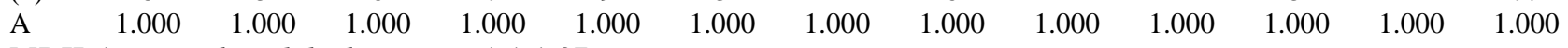
MDH-1 malate dehydrogenase 1.1.1.37

$\begin{array}{llllllllllllll}\text { (n) } & 8 & 6 & 6 & 4 & 9 & 3 & 4 & 6 & 1 & 4 & 5 & 23 & 77\end{array}$

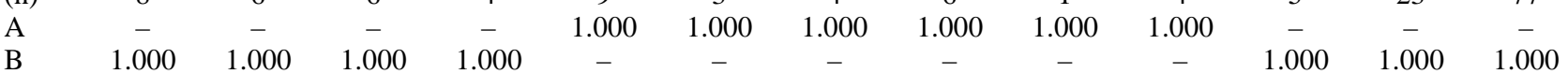
MDH-2 malate dehydrogenase 1.1.1.37

\begin{tabular}{lllllllllllll} 
(n) & 8 & 6 & 6 & 7 & 9 & 3 & 4 & 6 & 1 & 4 & 5 & 23 \\
\hline
\end{tabular}

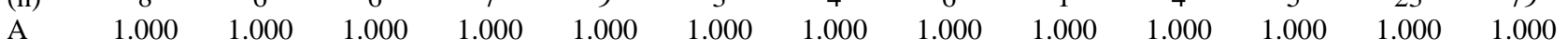
MPI mannose-6-phosphate isomerase 5.3.1.8

$\begin{array}{lccccccccccccc}\text { (n) } & 8 & 6 & 6 & 7 & 2 & 3 & 3 & 6 & 1 & 4 & 5 & 22 & 78 \\ \text { A } & - & - & - & 0.071 & - & - & - & - & - & - & - & 0.409 & 0.019 \\ \text { B } & 1.000 & 1.000 & 1.000 & 0.929 & 1.000 & 1.000 & 1.000 & 1.000 & 1.000 & 1.000 & 1.000 & 0.591 & 0.974 \\ \text { C } & - & - & - & - & - & - & - & - & - & - & - & 0.006 & - \\ \text { PEP:LA } & & \text { peptidase leucine-alanine substrate } & \mathbf{3 . 4 . 1 3} .- & & & & & & \end{array}$

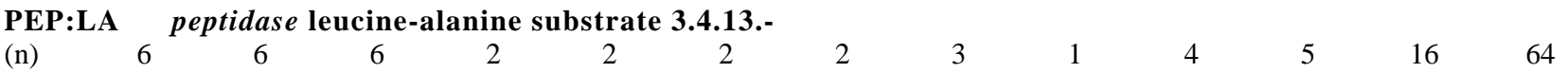

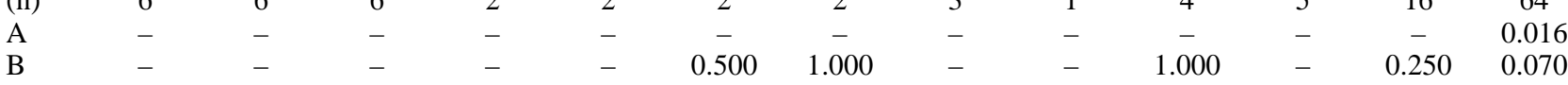

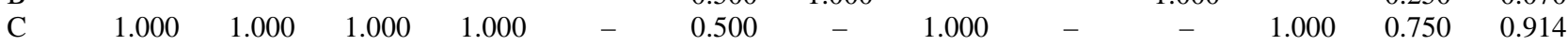

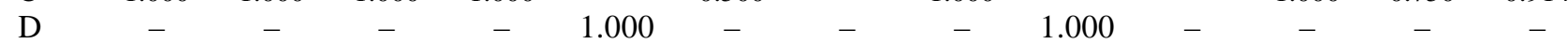

PEP:LGG peptidase leucine-glycine-glycine substrate 3.4.13.-

\begin{tabular}{|c|c|c|c|c|c|c|c|c|c|c|c|c|c|}
\hline (n) & 7 & 6 & 6 & 7 & 2 & 3 & 4 & 6 & 1 & 4 & 1 & 22 & 75 \\
\hline A & - & - & 0.083 & - & 1.000 & - & - & - & - & 1.000 & - & 0.045 & 0.033 \\
\hline B & 0.929 & 0.750 & 0.750 & 0.857 & - & 1.000 & 1.000 & 0.167 & - & - & 1.000 & 0.955 & 0.933 \\
\hline $\mathrm{C}$ & 0.071 & 0.250 & 0.167 & 0.143 & - & - & - & 0.833 & 0.500 & - & - & - & 0.033 \\
\hline D & - & - & - & - & - & - & - & - & 0.500 & - & - & - & - \\
\hline
\end{tabular}

PEP:PP peptidase phenylalanine-proline substrate 3.4.13.-

\begin{tabular}{|c|c|c|c|c|c|c|c|c|c|c|c|c|c|}
\hline (n) & 8 & 5 & 6 & 7 & 2 & 3 & 4 & 6 & 1 & 4 & 5 & 23 & 76 \\
\hline A & - & - & 0.167 & 0.214 & 1.000 & 1.000 & 1.000 & 1.000 & 1.000 & - & 1.000 & 0.022 & 0.039 \\
\hline B & 1.000 & 1.000 & 0.833 & 0.786 & - & - & - & - & - & 1.000 & - & 0.978 & 0.961 \\
\hline
\end{tabular}

\section{PGDH phosphogluconate dehydrogenase 1.1.1.44}

\begin{tabular}{llllllllllllll} 
(n) & 8 & 5 & 6 & 7 & 9 & 3 & 4 & 6 & 1 & 4 & 5 & 23 & 77 \\
A & - & - & - & - & - & - & - & - & - & - & - & - & 0.006 \\
B & - & - & - & - & - & - & - & - & - & - & - & - & 0.013 \\
C & - & - & - & - & - & - & - & - & - & - & - & - & 0.006 \\
D & - & - & - & - & - & 1.000 & 1.000 & 1.000 & 1.000 & - & - & 0.065 & 0.065 \\
E & - & - & - & 1.000 & 1.000 & - & - & - & - & 1.000 & - & - & - \\
F & 1.000 & 1.000 & 0.917 & - & - & - & - & - & - & - & 0.800 & 0.891 & 0.909 \\
G & - & - & 0.083 & - & - & - & - & - & - & - & 0.200 & - & - \\
H & - & - & - & - & - & - & - & - & - & - & - & 0.043 & - \\
PGM & & phosphoglucomutase 5.4.2.2 & & & & & & & & \\
(n) & 8 & 6 & 6 & 7 & 9 & 3 & 4 & 6 & 1 & 4 & 5 & 23 & 79 \\
A & - & - & - & - & - & - & 0.250 & - & - & - & - & - & - \\
B & 1.000 & 1.000 & 1.000 & 0.929 & 1.000 & 1.000 & 0.750 & 1.000 & 1.000 & 1.000 & - & - \\
C & - & - & - & 0.071 & - & - & - & - & - & - & 1.000 & 0.957 & 0.222 \\
D & - & - & - & - & - & - & - & - & - & - & - & 0.043 & 0.778 \\
\hline
\end{tabular}


Table 2. Matrix of genetic distances between Caledoniscincus populations. The figures below the diagonal are Nei (1978) unbiased genetic distances and those above the diagonal are the percentage of fixed differences. Population identifications are the same as for Table 1. Idhp-1 nulls are not included in fixed difference calculations; austro. $=$ austrocaledonicus.

\begin{tabular}{|c|c|c|c|c|c|c|c|c|c|c|c|c|c|}
\hline population: & 1 & 2 & 3 & 4 & 5 & 6 & 7 & 8 & 9 & 10 & 11 & 12 & 13 \\
\hline 1 C. aquilonius 1 & & 0 & 0 & 15 & 30 & 20 & 25 & 20 & 40 & 20 & 30 & 20 & 15 \\
\hline 2 C. aquilonius 2 & 0.007 & & 0 & 15 & 30 & 20 & 25 & 20 & 40 & 20 & 30 & 20 & 15 \\
\hline 3 C. aquilonius 3 & 0.010 & 0.035 & & 15 & 20 & 15 & 20 & 15 & 35 & 15 & 25 & 20 & 10 \\
\hline 4 C. terma & 0.106 & 0.097 & 0.128 & & 25 & 20 & 25 & 20 & 40 & 20 & 25 & 25 & 15 \\
\hline 5 C. auratus & 0.529 & 0.506 & 0.518 & 0.400 & & 20 & 20 & 20 & 25 & 2 & 40 & 35 & 25 \\
\hline 6 C. renevieri 1 & 0.321 & 0.312 & 0.342 & 0.345 & 0.271 & & 0 & 0 & 25 & 35 & 30 & 30 & 15 \\
\hline 7 C. renevieri 2 & 0.382 & 0.372 & 0.406 & 0.407 & 0.295 & 0.010 & & 5 & 30 & 35 & 35 & 30 & 15 \\
\hline 8 C. renevieri 3 & 0.346 & 0.315 & 0.350 & 0.361 & 0.281 & 0.044 & 0.092 & & 20 & 35 & 30 & 30 & 15 \\
\hline 9 C. cryptos & 0.715 & 0.695 & 0.705 & 0.777 & 0.345 & 0.350 & 0.375 & 0.329 & & 45 & 45 & 50 & 30 \\
\hline 10 C. chazeaui & 0.298 & 0.277 & 0.322 & 0.275 & 0.356 & 0.376 & 0.364 & 0.423 & 0.719 & & 45 & 30 & 20 \\
\hline 11 C. orestes & 0.370 & 0.365 & 0.389 & 0.375 & 0.580 & 0.439 & 0.486 & 0.475 & 0.804 & 0.784 & & 25 & 20 \\
\hline 12 C. austro. & 0.258 & 0.250 & 0.300 & 0.289 & 0.723 & 0.539 & 0.568 & 0.599 & 0.961 & 0.580 & 0.380 & & 20 \\
\hline 13 C. haplorhinus & 0.246 & 0.237 & 0.281 & 0.285 & 0.577 & 0.488 & 0.531 & 0.526 & 0.997 & 0.509 & 0.327 & 0.305 & \\
\hline
\end{tabular}

Table 3. Distribution of key diagnostic characters for all species of Caledoniscincus; austr. $\mathrm{s}=$ southern population (Noumea), austr. $\mathrm{n}=$ northern and central populations (Mt Aoupinié), species' names abbreviated to first five letters.

\begin{tabular}{|c|c|c|c|c|c|c|c|c|c|c|c|c|c|}
\hline & \multirow{2}{*}{$\begin{array}{l}\text { SIZE } \\
(\mathrm{SVL}) \\
\text { range }\end{array}$} & \multicolumn{2}{|c|}{$\begin{array}{c}\text { TL } \\
(\% \text { SVL) }\end{array}$} & \multicolumn{2}{|c|}{ DSR } & \multicolumn{2}{|c|}{ MBR } & \multirow{2}{*}{$\begin{array}{l}\text { post- } \\
\text { sacral } \\
\text { range }\end{array}$} & \multirow[b]{2}{*}{$\overline{\mathrm{x}}$} & \multirow{2}{*}{$\begin{array}{l}\text { vertebral } \\
\text { stripe }\end{array}$} & \multirow{2}{*}{$\begin{array}{l}\text { mid- } \\
\text { lateral } \\
\text { stripe }\end{array}$} & \multirow{2}{*}{$\begin{array}{c}\text { dark } \\
\text { midrostral } \\
\text { streak }\end{array}$} & \multirow{2}{*}{$\begin{array}{c}\text { adult male } \\
\text { ventral } \\
\text { colour }\end{array}$} \\
\hline & & range & $\overline{\mathrm{x}}$ & range & $\overline{\mathrm{x}}$ & range & $\overline{\mathrm{x}}$ & & & & & & \\
\hline aquil. & 39-49 & $146-163$ & 155 & $54-58$ & 55.8 & $30-34$ & 32.2 & $40-44$ & 43.5 & yes & yes & no & orange \\
\hline terma. & $41-50$ & $131-140$ & 136 & $55-63$ & 58.9 & $32-34$ & 32.4 & $37-38$ & 37.5 & no & yes & no & yellow \\
\hline renev. & $37-51$ & $127-154$ & 140 & $51-58$ & 53.6 & $30-32$ & 30.3 & $41-44$ & 42.7 & $+1-$ & yes & no & yellow \\
\hline aurat. & $38-51$ & $141-151$ & 147 & $52-55$ & 53.6 & 28 & - & $43-45$ & 44.0 & yes & yes & no & yellow \\
\hline chaze. & $36-43$ & & 136 & $59-61$ & 59.8 & $28-30$ & 29.0 & & 42 & yes & ves & no & $?$ \\
\hline crypt. & 45 & - & - & & 51 & & 30 & - & - & yes & $\equiv$ & no & $?$ \\
\hline orest. & $47-63$ & - & - & $55-63$ & 57.9 & $32-36$ & 32.8 & & 50 & no & & no & orange \\
\hline austr.s & $39-46$ & - & 155 & $56-62$ & 59.9 & $28-30$ & 29.5 & - & $>46$ & no & yes & no & orange \\
\hline austr. $\mathrm{n}$ & $44-57$ & - & $\approx 150$ & $58-65$ & 61.2 & $30-32$ & 31.2 & - & $>50$ & no & no & no & orange \\
\hline haplo. & $42-55$ & $156-174$ & 165 & $59-67$ & 63.0 & $28-32$ & 30.0 & $51-55$ & 52.3 & no & no & no & yellow \\
\hline festi. & $59-72$ & $131-160$ & 150 & $60-66$ & 61.9 & $32-34$ & 32.9 & $49-56$ & 52.1 & yes & yes & no & yellow \\
\hline atrop. & $38-53$ & $142-153$ & 150 & $51-60$ & 55.9 & $28-32$ & 29.6 & $49-51$ & 50 & yes & yes & yes & ?yellow \\
\hline
\end{tabular}


Table 2. Matrix of genetic distances between Caledoniscincus populations. The figures below the diagonal are Nei (1978) unbiased genetic distances and those above the diagonal are the percentage of fixed differences. Population identifications are the same as for Table 1. Idhp-1 nulls are not included in fixed difference calculations; austro. $=$ austrocaledonicus.

\begin{tabular}{|c|c|c|c|c|c|c|c|c|c|c|c|c|c|}
\hline population: & 1 & 2 & 3 & 4 & 5 & 6 & 7 & 8 & 9 & 10 & 11 & 12 & 13 \\
\hline 1 C. aquilonius 1 & & 0 & 0 & 15 & 30 & 20 & 25 & 20 & 40 & 20 & 30 & 20 & 15 \\
\hline 2 C. aquilonius 2 & 0.007 & & 0 & 15 & 30 & 20 & 25 & 20 & 40 & 20 & 30 & 20 & 15 \\
\hline 3 C. aquilonius 3 & 0.010 & 0.035 & & 15 & 20 & 15 & 20 & 15 & 35 & 15 & 25 & 20 & 10 \\
\hline 4 C. terma & 0.106 & 0.097 & 0.128 & & 25 & 20 & 25 & 20 & 40 & 20 & 25 & 25 & 15 \\
\hline 5 C. auratus & 0.529 & 0.506 & 0.518 & 0.400 & & 20 & 20 & 20 & 25 & 25 & 40 & 35 & 25 \\
\hline 6 C. renevieri 1 & 0.321 & 0.312 & 0.342 & 0.345 & 0.271 & & 0 & 0 & 25 & 35 & 30 & 30 & 15 \\
\hline 7 C. renevieri 2 & 0.382 & 0.372 & 0.406 & 0.407 & 0.295 & 0.010 & & 5 & 30 & 35 & 35 & 30 & 15 \\
\hline 8 C. renevieri 3 & 0.346 & 0.315 & 0.350 & 0.361 & 0.281 & 0.044 & 0.092 & & 20 & 35 & 30 & 30 & 15 \\
\hline 9 C. cryptos & 0.715 & 0.695 & 0.705 & 0.777 & 0.345 & 0.350 & 0.375 & 0.329 & & 45 & 45 & 50 & 30 \\
\hline 10 C. chazeaui & 0.298 & 0.277 & 0.322 & 0.275 & 0.356 & 0.376 & 0.364 & 0.423 & 0.719 & & 45 & 30 & 20 \\
\hline 11 C. orestes & 0.370 & 0.365 & 0.389 & 0.375 & 0.580 & 0.439 & 0.486 & 0.475 & 0.804 & 0.784 & & 25 & 20 \\
\hline 12 C. austro. & 0.258 & 0.250 & 0.300 & 0.289 & 0.723 & 0.539 & 0.568 & 0.599 & 0.961 & 0.580 & 0.380 & & 20 \\
\hline 13 C. haplorhinus & 0.246 & 0.237 & 0.281 & 0.285 & 0.577 & 0.488 & 0.531 & 0.526 & 0.997 & 0.509 & 0.327 & 0.305 & \\
\hline
\end{tabular}

Table 3. Distribution of key diagnostic characters for all species of Caledoniscincus; austr. s = southern population (Noumea), austr. $\mathrm{n}=$ northern and central populations (Mt Aoupinié), species' names abbreviated to first five letters.

\begin{tabular}{|c|c|c|c|c|c|c|c|c|c|c|c|c|c|}
\hline & \multirow{2}{*}{$\begin{array}{l}\text { SIZE } \\
\text { (SVL) } \\
\text { range }\end{array}$} & \multicolumn{2}{|c|}{$\begin{array}{c}\mathrm{TL} \\
(\% \mathrm{SVL})\end{array}$} & \multicolumn{2}{|c|}{ DSR } & \multicolumn{2}{|c|}{ MBR } & \multirow{2}{*}{$\begin{array}{l}\text { post- } \\
\text { sacral } \\
\text { range }\end{array}$} & \multirow[b]{2}{*}{$\overline{\mathrm{X}}$} & \multirow{2}{*}{$\begin{array}{l}\text { vertebral } \\
\text { stripe }\end{array}$} & \multirow{2}{*}{$\begin{array}{l}\text { mid- } \\
\text { lateral } \\
\text { stripe }\end{array}$} & \multirow{2}{*}{$\begin{array}{c}\text { dark } \\
\text { midrostral } \\
\text { streak }\end{array}$} & \multirow{2}{*}{$\begin{array}{c}\text { adult male } \\
\text { ventral } \\
\text { colour }\end{array}$} \\
\hline & & range & $\overline{\mathrm{x}}$ & range & $\overline{\mathrm{x}}$ & range & $\overline{\mathrm{x}}$ & & & & & & \\
\hline aquil. & 39-49 & $146-163$ & 155 & $54-58$ & 55.8 & $30-34$ & 32.2 & $40-44$ & 43.5 & no & no & yes & orange \\
\hline terma. & $41-50$ & $131-140$ & 136 & $55-63$ & 58.9 & $32-34$ & 32.4 & $37-38$ & 37.5 & yes & no & yes & yellow \\
\hline renev. & $37-51$ & $127-154$ & 140 & $51-58$ & 53.6 & $30-32$ & 30.3 & $41-44$ & 42.7 & $+1-$ & no & yes & yellow \\
\hline aurat. & $38-51$ & $141-151$ & 147 & $52-55$ & 53.6 & 28 & - & $43-45$ & 44.0 & no & no & yes & yellow \\
\hline chaze. & $36-43$ & & 136 & $59-61$ & 59.8 & $28-30$ & 29.0 & & 42 & no & no & yes & $?$ \\
\hline crypt. & 45 & - & - & & 51 & & 30 & - & - & no & no & yes & $?$ \\
\hline orest. & $47-63$ & - & - & $55-63$ & 57.9 & $32-36$ & 32.8 & & 50 & yes & no & yes & orange \\
\hline austr.s & $39-46$ & - & 155 & $56-62$ & 59.9 & $28-30$ & 29.5 & - & $>46$ & yes & no & yes & orange \\
\hline austr. $\mathrm{n}$ & $44-57$ & - & $\approx 150$ & $58-65$ & 61.2 & $30-32$ & 31.2 & - & $>50$ & yes & yes & yes & orange \\
\hline haplo. & $42-55$ & $156-174$ & 165 & $59-67$ & 63.0 & $28-32$ & 30.0 & $51-55$ & 52.3 & yes & yes & yes & yellow \\
\hline festi. & 59-72 & $131-160$ & 150 & $60-66$ & 61.9 & $32-34$ & 32.9 & $49-56$ & 52.1 & no & no & yes & yellow \\
\hline atrop. & $38-53$ & $142-153$ & 150 & $51-60$ & 55.9 & $28-32$ & 29.6 & $49-51$ & 50 & no & no & no & ?yellow \\
\hline
\end{tabular}

\footnotetext{
* corrections to Table 3 are printed on this replacement page (15 September 1999).
} 


\section{Appendix 1}

Registration numbers and corresponding tissue numbers (in brackets) for the specimens of Caledoniscincus used in the electrophoretic study. For each species a generalised place name for each population sampled is given, and listed in a north to south order.

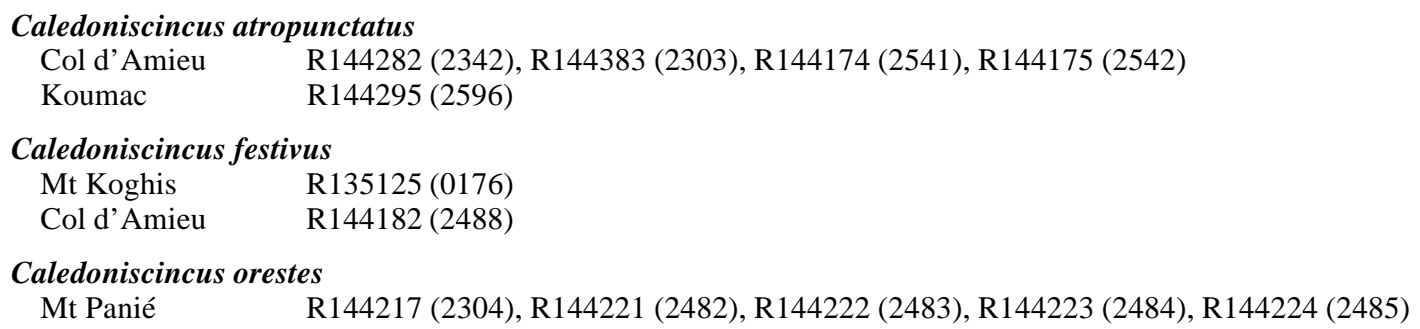

\section{Caledoniscincus austrocaledonicus}

Mandjélia $\quad$ R146322 (2830), R146323 (2831), R146324 (2832), R146325 (2833)

Ouaï̀me $\quad$ R144239 (2293), R144240 (2294), R144243 (2550), R144244 (2551), R144245 (2552), R144246 (2553)

Koulnoué R138326 (0817), R138327 (0818)

Poindimié $\quad$ R144270 (2563), R144271 (2564), R144265 (2588), R144266 (2589), R144267 (2590), R144268 (2591)

Mt Aoupinié $\quad$ R146386 (2887), CAS 198720 (2888), CAS 198725 (2885), CAS 198726 (2886), R146379 (3001), R146380 (3002)

Adio Caves R146503 (3030), R146504 (3031)

Poya $\quad$ CAS 198672 (2820), R146307 (3070), R146308 (3071), R146309 (3072)

Col des Roussettes R146398 (2906), R146432 (2944)

Col d'Amieu R144163 (2308), R144164 (2309), R144165 (2310), R144166 (2543), R144167 (2544), R144168 (2545)

Sarraméa $\quad$ R144112 (2315), R144113 (2316), R144114 (2546), R144115 (2547), R144116 (2548), R144117 (2549)

Plateau de Dogny $\quad$ R144137 (2284), R144138 (2285), R144284 (2489), R144285 (2490), R144286 (2491), R144287 (2492)

Mt Do CAS $198674(2922)$

Tomo R146294 (2810), R146295 (2811), R146296 (2812), R146297 (2813)

Nouméa $\quad$ R135114 (0165), R135115 (0166), R135116 (0167), R135117 (0168), R135118 (0169)

Mt Koghis R135126(0177), R135127 (0178)

Rivière Bleue $\quad$ R135133(0182), R135134(0183), R135135 (0184), R135136 (0185)

Ile des Pins $\quad$ R138559(0804), R138560 (0805), R138561 (0845), R138646 (0846)

\section{Caledoniscincus haplorhinus}

Koumac $\quad$ R144284 (2289), R144285 (2290), R144257 (2538), R144258 (2539), R144288 (2593), R144289 (2594)

Tomo R146301 (2816), R146302 (2817), CAS 198669 (2818), CAS 198670 (2819)

Plage de Pindaï R146461 (2993), R146462 (2994), R146463 (2995), R146464 (2996)

Plage de Ouano R146436 (2946), CAS 198763 (2947), R146437 (2948), CAS 198764 (2594)

Nouméa $\quad$ R135119 (0170), R135120 (0171), R135121 (0172), R135122 (0173), R135123 (0174)

\section{Caledoniscincus aquilonius}

Kavaatch $\quad$ R144249 (2555), R144252 (2296), R144250 (2556), R144251 (2557), R144253 (2297), CAS 182062 (0830)

Mt Panié $\quad$ R144199 (2322), 144206 (2529), R144227 (2480), R144200 (2323), R144207 (2530), R144228 (2481)

Koumac R144296(2298), R144297 (2299), R144259(2540), R144380(2597), R146338 (2839), R146339 (2840), R146340 (2841), R146341 (2842)

\section{Caledoniscincus terma}

Mt Mandjélia $\quad$ R146316 (2827), CAS 198680 (2828), R146346 (2844), R146344 (3003), R146345 (3004), R146320 (3005), R146321 (3006)

\section{Caledoniscincus renevieri}

Mt Aoupinié $\quad$ R146382 (2932), R146383 (2933), R146384 (2934)

Adio Caves $\quad$ R146499 (3026), R146500 (3027), R146501 (3028), AMB 4466 (3029)

Col des Roussettes R146392 (2895), R146393 (2896), R146394 (2897), R146395 (2898), CAS 198745 (2938), R146423 (3008)

\section{Caledoniscincus chazeaui}

Koulnoué $\quad$ CAS 182073 (0819), CAS 182074 (0820), R138515 (0821), R138516 (0822)

\section{Caledoniscincus auratus}

Koumac $\quad$ R144298 (2300), R144299(2301), R144300 (2302), R144301 (2476), R144302 (2477), R144303 (2478), R144304

(2479), R144381 (2598), R144382 (2599)

\section{Caledoniscincus cryptos}
Col d'Amieu
R135141 (0188) 